\title{
The Dynamic Advertising Effect of Collegiate Athletics
}

\section{Citation}

Chung, Doug J. "The Dynamic Advertising Effect of Collegiate Athletics." Harvard Business School Working Paper, No. 13-067, January 2013.

\section{Published Version}

http://dx.doi.org/10.1287/mksc.2013.0795

\section{Permanent link}

http://nrs.harvard.edu/urn-3:HUL.InstRepos:10304546

\section{Terms of Use}

This article was downloaded from Harvard University's DASH repository, and is made available under the terms and conditions applicable to Open Access Policy Articles, as set forth at http:// nrs.harvard.edu/urn-3:HUL.InstRepos:dash.current.terms-of-use\#OAP

\section{Share Your Story}

The Harvard community has made this article openly available.

Please share how this access benefits you. Submit a story.

Accessibility 
H A R VAR D

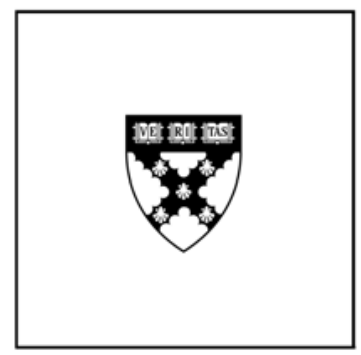

\title{
The Dynamic Advertising Effect of Collegiate Athletics
}

\author{
Doug J. Chung
}

\section{Working Paper}

13-067

January 31, 2013 


\section{The Dynamic Advertising Effect of Collegiate Athletics}

Doug J. Chung*

January 2013

* Doug J. Chung is an Assistant Professor of Business Administration at Harvard Business School (dchung@hbs.edu). The author would like to thank K. Sudhir, Ahmed Khwaja, Oliver Rutz, Subrata Sen, Kevin Keller Lane, Neil Bendle, Colin Campbell, Boudhayan Sen, Jennifer Danilowitz, Sue Kim, and the seminar participants at the 2012 INFORMS Marketing Science Conference and the Yale SOM Doctoral Workshop for their comments and suggestions. 


\title{
The Dynamic Advertising Effect of Collegiate Athletics
}

\begin{abstract}
I measure the spillover effect of intercollegiate athletics on the quantity and quality of applicants to institutions of higher education in the United States, popularly known as the "Flutie Effect." I treat athletic success as a stock of goodwill that decays over time, similar to that of advertising. A major challenge is that privacy laws prevent us from observing information about the applicant pool. I overcome this challenge by using order statistic distribution to infer applicant quality from information on enrolled students. Using a flexible random coefficients aggregate discrete choice model - which accommodates heterogeneity in preferences for school quality and athletic success - and an extensive set of school fixed effects to control for unobserved quality in athletics and academics, I estimate the impact of athletic success on applicant quality and quantity. Overall, athletic success has a significant long-term goodwill effect on future applications and quality. However, students with lower than average SAT scores tend to have a stronger preference for athletic success, while students with higher SAT scores have a greater preference for academic quality. Furthermore, the decay rate of athletics goodwill is significant only for students with lower SAT scores, suggesting that the goodwill created by intercollegiate athletics resides more extensively with low-ability students than with their high-ability counterparts. But, surprisingly, athletic success impacts applications even among academically stronger students.
\end{abstract}




\section{Introduction}

On a stormy day in November 1984, Boston College and the University of Miami played an extraordinary football game. It was an electrifying shootout, with 1,273 yards of total offense and multiple lead changes throughout the game. However, the final play of the game is what has captivated the minds of sports fans all over the United States for decades. The score was Miami 45, Boston College 41 and, with only six seconds remaining in the ball game, Boston College quarterback Doug Flutie made a miraculous Hail Mary touchdown pass to win the game. ${ }^{1}$ This game was nationally televised the day after Thanksgiving and thus, had a huge viewing audience. As a result of the win, Boston College qualified to compete in one of the New Year's bowl games, the Cotton Bowl, and finished the season with a 10-2 record and a top-five AP (Associated Press) Poll ranking. ${ }^{2}$ Doug Flutie won the Heisman Trophy, the most prestigious individual award in college football, and went on to have a successful career as a professional football player and TV analyst.

Two years following this extraordinary game, Boston College enjoyed a surge of approximately 30 percent in its applications. Ever since, the popular media have called this phenomenon the "Flutie Effect," referring to an increase in exposure and prominence of an academic institution due to the success of its athletics program. As USA Today described it, "Whether it's called the 'Flutie factor' or 'mission-driven intercollegiate athletics,' the effect of having a winning sports team is showing up at admissions offices nationwide." ${ }^{3}$

Boston College is not alone in witnessing a surge of applications due to success on the field. Applications at Georgetown University rose 45 percent between 1983 and 1986, a period in which it had tremendous success in men's basketball, appearing three times in the National Collegiate Athletic Association (NCAA) championship finals. Northwestern University saw a

\footnotetext{
${ }^{1}$ A Hail Mary pass is a term used to describe a long forward pass that has a very small probability of success. It usually is called into play toward the end of a game in which it is the only option for winning.

${ }^{2}$ At the time, the schools with the most successful regular seasons were invited to one of five New Year's bowl games: the Cotton, Fiesta, Orange, Rose, and Sugar Bowls. Multiple polls decide the rankings of schools in college football: the AP Poll, the Coaches Poll, the Harris Interactive Poll, etc. The oldest of these polls, the AP Poll, is compiled by sports writers across the United States and is most commonly used to determine the success of a particular school's football season.

3 Source: "Winning One for the Admissions Office," USA Today, July 11, 1997.
} 
21-percent increase in applications in 1995, a year after winning the Big Ten Championship in football.

More recently, Boise State University enjoyed an 18-percent increase in applications after the 2006-07 football season, which it topped off with a win over college football powerhouse, University of Oklahoma, in the 2007 Fiesta Bowl to cap a perfect 13-0 season. Texas Christian University (TCU), after decades of mediocrity in college football, was able to land in the AP Top 25 rankings for the first time in over 40 years in 2000. Ever since, TCU has frequently been in the top of the college football rankings, enjoying media exposure with many nationally televised games. Its admissions office also enjoyed a whopping 105-percent increase in applications from 2000 to 2008.

However, is the so-called "Flutie Effect" for real? Boston College's admissions director at that time, John Maguire, does not seem to think so. "Doug Flutie cemented things, but the J. Donald Monan factor and the Frank Campanella factor are the real story," he said, referring to Boston College's former president and executive vice president. Maguire believes that Boston College experienced a surge in applications in the mid-1980s due to its investments in residence halls, academic facilities, and financial aid. So he claims that the "Flutie Effect" was minimal, at best, and did not contribute as much as the popular press claimed it had. ${ }^{4}$

The primary form of mass media advertising by academic institutions in the United States is, arguably, through its athletics program. Therefore, this study investigates the possible advertising effects of intercollegiate athletics. Specifically, it looks at the spillover effect, if any, and the magnitude and divergence that athletic success has on the quantity and quality of applications received by an academic institution of higher education in the United States. Furthermore, I look at how students of different abilities place heterogeneous values on athletic success versus academic quality.

For many people residing in the United States, intercollegiate athletics is a big part of their everyday lives. During the college football season, it is common to see live college football games being broadcast in prime time slots, not only by sports-affiliated cable channel

\footnotetext{
${ }^{4}$ Source: "The 'Flutie factor' is now received wisdom. But is it true?" Boston College Magazine, Spring 2003.
} 
networks (e.g., ESPN and Fox Sports), but also by the major over-the-air networks (ABC, NBC, and CBS). ${ }^{5} \quad$ Yet, it is surprising to see very limited research in this area.

McCormick and Tinsley (1987) were the first to examine the possible link between athletics and academics. They find that, on average, schools in major athletic conferences tend to attract higher-quality students than those in non-major conferences and that the trend in the percentage of conference wins in football is positively correlated with the increase in the quality of incoming students. They hypothesize that intercollegiate athletics has an advertising effect and, as a result, suggest that schools with athletic success may receive a greater number of applications, thus allowing them to be more selective in admissions. Similar to McCormick and Tinsley (1987), Tucker and Amato (1993), using a different time frame for the data, find that football success increases the quality of incoming students. Using only a single year of school information, these studies rely primarily on cross-sectional identification to determine the impact of historical athletic success on the quality of the incoming freshman class, essentially ignoring any unobserved school-specific effects that might be correlated with athletic success.

In comparison, Murphy and Trandel (1994) and Pope and Pope (2009), using panel data, focus more on short-term episodic athletic success and its impact on academics. While these studies, in aggregate, are able to control for unobserved school-specific effects, by relying solely on a descriptive model, they are unable to precisely capture shifts in preferences by potential students. In addition, aside from Pope and Pope (2009), all of the above studies ignore any heterogeneous effects of athletics on students of different ability. Furthermore, these studies use institutional-level data, disregarding any specific market-level characteristics that would likely affect demand for higher education in different markets. i.e. both Murphy and Trandel (1994) and Pope and Pope (2009) use the aggregate number of applications per institution per year as their observation points, while I use market-level (state-level) data to infer school preferences for students who reside in different markets. Moreover, by examining only changes in the aggregate, these studies do not account for any heterogeneity in preferences

\footnotetext{
5 ABC's Saturday Night Football, which broadcasts major college football games live, runs from 8:00 PM to 12:00 PM on Saturday evenings during the college football season. More information about the popularity of college football is given in the following sections.
} 
for athletic success that is likely to exist among high school seniors applying to colleges and universities in the United States. Most importantly, none of the above studies accounts for the relative value of athletic success compared to other factors (monetary/psychological costs, academic quality, etc.) that determine an applicant's choice of demand for higher education.

I distinguish from these studies and treat athletic success as a stock of goodwill that decays over time, similar to that of advertising. Relying on the utility-maximizing behavior of high school seniors applying to colleges and universities in the United States, I build and estimate a structural model of demand for higher education to determine the effect and magnitude that these goodwill stocks can have on the outcome of school admissions. My goal is twofold: to determine if there is, indeed, an advertising spillover effect from athletic success and, if so, to identify the magnitude of the effect on the quality and quantity of applications and its impact on school selectivity rates. Furthermore, using market-level data, I examine the relative importance of athletic success compared to other factors (academic quality, tuition costs, distance from home, etc.) that influence students of different abilities.

From a modeling perspective, using an extensive set of school fixed effects to control for unobserved quality in athletics and academics, I apply a flexible random coefficients aggregate discrete choice model to allow for heterogeneity in preferences where athletic success shifts school preferences for high school seniors applying to colleges and universities. A major challenge is that privacy laws prevent us from observing information about the applicant pool. I overcome this challenge by developing an order statistics based approach to infer applicant quality from information on enrolled students.

Overall, I find that athletic success has a significant impact on the quantity and quality of applicants that a school receives. However, I find that students with lower than average SAT scores have a stronger preference for athletic success, while students with higher SAT scores have a greater preference for academic quality. Furthermore, I find that the carryover rate of goodwill stocks for athletic success is evident only for students with lower SAT scores, suggesting that students of low ability intertemporally value the success of intercollegiate athletics more and discount it less than their high-ability counterparts. In addition, I find that when a school goes from being "mediocre" to being "great" on the football 
field, applications increase by 18.7 percent, with the vast proportion of the increase coming from low-ability students. However, there is also an increase in applications from students at the highest quality level. In order to attain similar effects, a school must either decrease its tuition by 3.8 percent or increase the quality of its education by recruiting higher-quality faculty who are paid five percent more in the academic labor market. I also find schools become more selective with athletic success. For the mid-level school in terms of average SAT scores, the admissions rate would drop by 5.1 percent with high-level athletic success.

The rest of the paper proceeds as follows. Section 2 presents an overview of collegiate athletics and the data used for empirical analysis. Sections 3 and 4 present the model and estimation methodology, respectively. Section 5 discusses the results and counterfactual analysis, and Section 6 concludes.

\section{Collegiate Athletics and the Data}

\subsection{Collegiate Athletics}

The first college football game was played between Rutgers University and Princeton University in 1869. The last years in which a non-athletic scholarship granting school won a major title in college football were in the mid-1940s and early-1950s, with Princeton University and the United States Military Academy winning the College Football National Championship in 1950 and in 1944-1946, respectively. In those days, collegiate athletics was used mainly as a tool to increase diversity and to boost pride and self-awareness among the student body and alumni.

Things have substantially changed over the past several decades. While it is still true that one of its missions is to increase diversity and morale, today's collegiate athletics has become a multi-billion dollar industry, raking in huge amounts of revenue for the participating institutions. It acts as a huge catalyst in boosting the regional economy and at public institutions, it is not uncommon to see the head coaches as one of the highest-paid state employees. $\quad$ As for mere numbers, college football alone topped $\$ 2$ billion in revenue and $\$ 1.1$ billion in profit in 2010, and the single highest revenue-generating institution, the University of 
Texas at Austin, generated $\$ 94$ million of revenue in football alone. ${ }^{6}$ Nick Saban, the head football coach at the University of Alabama, is the highest paid coach, with an annual income of close to $\$ 6$ million. $^{7}$ The total fan base for college football is 103 million people, which represents approximately one-third of the U.S. population, and 43 percent of U.S. residents saw at least one of the 35 post-season bowl games in the $2010-11$ football season. ${ }^{8}$ I hereafter refer to the 2010-11 season as the 2010 season. The University of Nebraska holds the longest home game sell-out streak, dating back to 1962 (306 as of the end of the 2010 football season), and the average home game ticket price in the secondary market in 2009 for Ohio State was \$524, the highest among all schools. Though not the original goal when intercollegiate athletics was first implemented, it has become commercialized and is a significant part of the regional economy.

To investigate the effect of having a successful athletics program on admissions, I utilize multiple datasets. I compile each dataset to match one of the 120 institutions that participates in the NCAA Division 1 FBS (Football Bowl Subdivision).

As with professional sports, collegiate athletics has a hierarchy of divisions, with Division 1 as its highest level of competition. Within Division 1 are Division 1 FBS and Division 1 FCS (Football Championship Subdivision). ${ }^{9}$ Division 1 FBS is the strongest of all divisions and is considered as the main division. Therefore, my analysis focuses only on the set of institutions that participate in this division. ${ }^{10}$ Figure 1 outlines the subdivisions and conferences within Division 1.

\footnotetext{
${ }^{6}$ Source: "College football's $\$ 1.1$ billion profit," CNNMoney.com, December, 2010.

7 Source: "Football Bowl Subdivision coaches salaries for 2010," USA Today, December, 2010.

8 Source: "Behind the Numbers: College Football Business Grows Exponentially," CNBC.com, March, 2011.

9 These two subdivisions were formerly known as Division 1-A and Division 1-AA. The key organizational difference is that the former relies on bowl games after the regular season to determine the champion while the latter determines the champion through a playoff. The substantive difference is that the former utilizes many more resources than the latter and can award up to 85 athletic scholarships, compared to the former's 63 . Furthermore, Division 1 FBS teams have better facilities and a bigger alumni base, which results in larger amounts of contributions to support their athletic programs.

${ }^{10}$ While a majority of schools in Division 1 FBS jointly operate both football and basketball programs, there are some schools that are considered high-profile basketball programs, which are not part of this division. e.g., Georgetown, Gonzaga, etc.
} 
Presently, Division 1 FBS can still be divided into two subdivisions, referred to as the AQ (automatic qualifying) and non-AQ conferences (also known as the mid-majors). ${ }^{11}$ The main difference between them is that the conference champions of the AQ conferences are automatically invited to a BCS (Bowl Championship Series) bowl game at the end of the regular season, whereas invitations to such bowl games are more difficult to obtain for non-AQ conference teams. Although the definition of success varies according to the school and its pre-season expectations, a school is generally believed to have had a successful season if it goes to a BCS bowl game. ${ }^{12}$ Hence, the AQ conference schools tend to have superior facilities and funding and, as a result, attract more talented student athletes to their athletic programs.

\subsection{Data}

The primary data for admissions were collected through the Integrated Postsecondary Education Data System (IPEDS), the core of the postsecondary education data collection program for the National Center for Educational Statistics (NCES). It contains data on the number of applications received, the number of applicants admitted, and the number and distribution of SAT scores for students enrolled at each institution of higher education. In addition, to correctly ascertain where the applications come from, I manually collected data from the College Board's (the implementers of the SAT) annual state-level report "CollegeBound Seniors." This dataset contains the exact number of SAT score reports sent by high school seniors in each state seeking admission to colleges and universities throughout the United States. It also contains the distribution of overall SAT scores by state.

Institutional characteristics such as average faculty salary, whether the school is a public or private institution, size of the student body, total number of faculty, and published in-state and out-of-state tuition costs were also collected through IPEDS. The historical number of high school graduates by state for each year over the sample period was collected

\footnotetext{
11 As of December 2010, the AQ conferences (also referred to as the Bowl Championship Series, or BCS, conferences) are the Atlantic Coast Conference (ACC), Big East Conference, Big Ten Conference, Big 12 Conference, Pacific (Pac)-10 Conference, and Southeastern Conference (SEC); the non-AQ conferences are the Conference USA (CUSA), Mid-American Conference (MAC), Mountain West Conference (MWC), Sun Belt Conference, and Western Athletic Conference (WAC).

12 Currently, the BCS bowl games are the Rose, Sugar, Fiesta, and Orange bowls, and the BCS National Championship Game.
} 
through the NCES. To control for inflation, the history of the consumer price index was obtained from the U.S. Bureau of Labor Statistics and used to convert any monetary variables in the analysis to 2009 U.S. dollars. The distance from a specific state to an institution was manually collected using publicly available software. ${ }^{13}$

Finally, athletic performance data were hand-collected from multiple data sources: Wikipedia, STASSEN.COM College Football Information, and Sports-Reference. As a measure of athletic performance, I use the total number of wins per season for the school's football program. Although slightly different by conference and season, Division 1 FBS teams typically play 12 games in a regular season. ${ }^{14}$ Bigger conferences, which have sub-conferences, hold a conference championship game between the sub-conference champions. ${ }^{15}$ After the regular season, teams with six or more wins qualify for a post-season bowl game; for each bowl game, a bowl committee selects the teams that will participate. As previously mentioned, the conference champions of AQ conferences automatically qualify for a BCS bowl game and the two top-ranking teams in the BCS standings play for the BCS National Championship. Thus, the maximum number of games that a team can win is 14, i.e., regular-season games (12) plus a conference championship (1) plus a bowl game (1). I hypothesize that with each additional win, a team would receive greater media exposure via TV, newspapers, and other media outlets, which would create an advertising effect for the school. Therefore, I use the total number of games won in a season to measure the success of a particular school's athletic performance.

Table 1 shows the descriptive statistics of the data. The AQ conference schools tend to receive more applications and have larger student bodies. The difference is clearer for private schools, with private schools of AQ conferences receiving twice as many applications as their non-AQ counterparts, despite their enrollment being relatively the same. Private schools are generally more selective in both subdivisions (AQ and non-AQ). They also tend to have

\footnotetext{
${ }^{13}$ The web tool Distance From To (http://distancefromto.net) was used to calculate the distances from students' home states to each institution.

${ }^{14}$ Teams that play at Hawaii have the option of scheduling a 13th regular-season game to offset travel costs. This rule, referred to as the "Hawaii Exemption," also gives the University of Hawaii the option of playing a 13th game.

${ }^{15}$ As of the 2010-11 season, the ACC, Big-12, CUSA, MAC, and SEC have a conference championship game in Division 1 FBS.
} 
better standards of education quality, with higher average faculty salaries and faculty-student ratios. Consequently, they generally have a propensity for attracting higher-quality students, as evidenced by higher average SAT scores. Overall, the schools in the AQ conferences are generally bigger, have higher standards of education, and tend to attract superior students, consistent with the results of past cross-sectional studies (e.g., McCormick and Tinsley, 1987) that find schools with successful athletics programs tend to attract higher-quality students.

Model-free analysis

Figure 2a shows the aggregate number of high school graduates in the United States over the past decade. There is an upward trend in the number of graduates, mainly due to the population increase in that age bracket.

To get a glimpse of how athletic success influences admissions, Figure 3a shows the number of applications received by the two main public universities in the state of Alabama, the University of Alabama and Auburn University. The reason for choosing these two institutions for illustration is that many consider them to be the biggest college football rivals in the United States, clashing each year in their historic rivalry game, the Iron Bowl. ${ }^{16}$ They are both public universities of roughly equal enrollment and academic rankings. In addition, college football is one of the biggest - if not the biggest - attractions in the state of Alabama, with the University of Alabama winning the BCS National Championship in the 2009 season and Auburn University winning it in the 2010 season. The early years of this decade are referred to as the "dark ages" in Crimson Tide (Alabama's nickname) football where the school had to deal with NCAA sanctions for recruiting violations. During this period, Alabama also lost the Iron Bowl to Auburn seven consecutive years. The football program was rejuvenated in the later years of the decade and has been on the national scene ever since. It actually was during this time frame that Alabama surpassed Auburn in the number of applications received.

The most established and well-known institution in college football is, arguably, the University of Notre Dame, with 13 recognized national championships under its belt and 96

${ }_{16}$ There are other big rivalries considered to be equal to the rivalry of Alabama and Auburn; Yale vs. Harvard, Army vs. Navy, Ohio State vs. Michigan, USC vs. Notre Dame, Stanford vs. California, Texas vs. Texas A\&M. 
All-Americans and seven Heisman Trophy winners throughout its history. ${ }^{17}$ Notre Dame has had somewhat of a rollercoaster ride in the past decade in terms of football success. Table 2 shows the overall football wins per season for a select number of schools. One can see that Notre Dame did quite well in the 2002, 2005, and 2006 seasons, with ten, nine, and ten wins, respectively. Since football season begins with the start of the academic year in the fall and ends with the conclusion of the national championship game in early January, and applications for admission are usually submitted between late fall to early spring of the previous academic year, the effect, if any, that football success has on the number of applications is anticipated to appear the following academic year. ${ }^{18}$ Figure $3 \mathrm{~b}$ shows that Notre Dame had substantial increases in the number of applications in 2003, 2006, and 2007, years immediately following successful football seasons. On the contrary, in other years, Notre Dame had only a limited increase and, in some instances, a decrease in the number of applications.

This phenomenon is not limited to the case of Notre Dame. Figure 3c shows the trend of applications for two large public institutions with rich traditions in football, the University of Texas and Pennsylvania State University. Similar to the application trends of Notre Dame, the number of applications for both Texas and Penn State increased significantly, immediately following years of football success. Specifically, there was a huge increase in the number of applications for Texas in the year following the BCS National Championship at the end of the 2005 football season. Likewise, there was a huge increase in applications for Penn State in the year following its win in a BCS bowl game, the Orange Bowl, at the end of the 2005 football season.

Would this phenomenon hold for smaller schools with less of a history of football success prior to the recent decade? The University of Oregon and the University of West Virginia, with their high-tempo powering offenses, have gained popularity among college football fans and have enjoyed huge success on the football field during the past decade. Figure 3d shows the application trends for both of these schools. The number of applications

\footnotetext{
17 Source: Wikipedia.

18 A more detailed description of timing is given in the following section.
} 
at both schools has risen substantially over the past decade, with peaks in the years following successful football seasons.

Finally, to offer a glimpse into what happens when a less sports-affiliated institution (member of the non-AQ conference) excels in athletics, Figure 3e shows the number of applications for TCU over the past decade. ${ }^{19}$ We see a huge increase in applications, far greater than the increase in high school graduates shown in Figure 2a. In the same period, unlike its football performance in the previous decades, TCU did quite well on the field, having been ranked in the top 10 twice and in the top 25 seven times in the final AP Poll.

One thing to consider is that there may have been a national temporal trend in the number of applications in the past decade due to record-low interest rates and the federal government's emphasis on postsecondary education. Figure $2 \mathrm{~b}$ shows the overall total number of applications for 1,277 U.S. institutions that offered associate degrees or above. The aggregate number of applications for these institutions increased substantially. Figure 2c shows the ratio of the number of applications to the total number of U.S. high school students over the past decade. The average number of applications per student steadily increased, with 1.4 applications per student in 2001 and 1.8 in 2009, possibly due to the macroeconomic variables mentioned above.

To account for this trend and to conduct a more general and conclusive analysis of the relation between football success and applications, Figure 4 shows a scatter plot and the bestfitting nonparametric smoothed polynomial (and its 95 percent confidence interval) of the fractional increase in applications (normalized by the total number of applications) against the change in the number of wins compared to the previous season. Normalization was done by dividing the number of applications for each institution by the total number of applications in a given year to account for macroeconomic temporal changes. Hence, the $y$-axis of Figure 4 is the fractional increase in the normalized number of applications, specifically,

19 TCU was a member of the MWC. As of July 1, 2012, it became a member of one of the AQ conferences, the Big 12. 
(The increase in normalized applications for institution $j$ at $t)=\frac{\left(\frac{a p p_{j t}}{\operatorname{Tapp}_{t}}-\frac{a p p_{j, t-1}}{\operatorname{Tapp}_{t-1}}\right)}{\left(\frac{a p p_{j, t-1}}{\operatorname{Tapp}_{t-1}}\right)}$,

where $\operatorname{Tapp}_{t}=\sum_{j} a p p_{j t}$. The $x$-axis is institution $j$ 's change in the number of wins compared to the previous football season. One can see that when there is no significant change in football performance (near zero on the $x$-axis), changes in the number of applications are minimal. However, when there is a substantial increase in football success (the right side of zero on the $x$-axis), applications increase substantially. In contrast, when there are negative changes in football performance (the left side of zero on the $x$-axis) there is a decline in normalized applications.

\section{Model}

I propose a model of demand for higher education that allows for heterogeneity in students' tastes for school and market characteristics. I treat athletics and its cumulative performance as a stock of goodwill that decays over time but augments with current performance, similar to that of advertising. ${ }^{20}$ In addition, I use order statistics to infer the quality of applicants from the observed distribution of the incoming freshman class and, thus, am able to formulate the relative importance of athletic success to students of different abilities. Model of application choice conditional on the quality of applicants

For most high school seniors, the choice of postsecondary education is probably the biggest decision they've faced in their young lives. When a student decides where to apply, she is likely basing her decision on factors related to the quality of education, such as the quality of the faculty and the faculty-student ratio. She probably also takes into account the opportunity costs of postsecondary education and costs related to attending a particular institution. These costs can be in the form of monetary costs, primarily represented by the

${ }^{20}$ Numerous studies deal with the long-term and carryover effects of advertising, e.g., de Kluyver and Brodie (1987), Givon and Horsky (1990), Dekimpe and Hanssens (1995), Lodish et al. (1995), Bruce (2008), and Rutz and Bucklin (2011). Clarke (1976) and Assmus et al. (1984) compare various models with regard to the long-term effect of advertising. 
cost of tuition, or the psychological costs of being away from home. Factors such as the diversity of the student body and the goodwill created by intercollegiate athletics may also affect her decision.

Let the utility of person $i$ with ability $a$ residing in state $s$ who decides to apply to institution $j$ at time $t$ be represented as $u_{i s j t}^{a}$. Obviously, the utility obtained from applying is not limited to simply "applying" but is more of a continuation value expected from enrolling in the school. Assume that the utility is additively separable between a deterministic component and a random component, and, hence, the utility function can be represented as

$$
u_{i s j t}^{a}=\sum_{k} \beta_{k}^{a} x_{s j k t}-\gamma^{a} p_{s j t}^{T}+G_{j t}^{a}+\xi_{j}^{a}+\Delta \xi_{s j t}^{a}+\sum_{k} \sigma_{k}^{a} x_{s j k t} \nu_{i s k}+\sigma_{p}^{a} p_{s j t}^{T} \nu_{i s p}+\varepsilon_{i s j t}^{a}
$$

where $x_{s j k t}$ is the $k$-th observed characteristic of the market institution-specific vector $x_{s j t}$. I define a market as the state in which a high school student currently resides. $\quad \xi_{j}^{a}$ is the time invariant unobserved (by the econometrician) utility component of $j$ that is common across all individuals (with ability $a$ ) and across all markets, and $\Delta \xi_{s j t}^{a}$ is the time-varying unobserved utility component of $j$ that is common across all individuals with ability $a$ in market $s$ at time $t$. The unobserved $\xi$ captures difficult-to-quantify aspects, such as prestige, tradition, and reputation, that affect the demand of institution $j . \quad \varepsilon_{i s j t}^{a}$ is the idiosyncratic random shock to utility that is assumed to be independently and identically distributed type I extreme value across individuals, states, schools and time. $p_{s j t}^{T}$ is the tuition costs, which are identical across markets for private institutions but differ by market for public institutions. Specifically, for public institutions,

$$
p_{s j t}^{T}=\left\{\begin{array}{lr}
\underline{p}_{s j t}^{T}, & \text { if institution } j \text { is in state } s \\
\bar{p}_{s j t}^{T}, & \text { otherwise }
\end{array},\right.
$$

where $\underline{p}_{s j t}^{T}$ and $\bar{p}_{s j t}^{T}$ represent the in-state and out-of-state tuition, respectively. $G_{j t}^{a}$ is the stock of goodwill generated by past and current athletic performance, which takes on the process as follows:

$$
G_{j t}^{a}=\lambda^{a} G_{j, t-1}^{a}+b^{a} A_{j t},
$$


where $\lambda$ is the carry-over rate $(1-\lambda$ can be thought of as the decay rate), which is assumed to be $0<\lambda<1$, and $A_{j t}$ is current athletic performance, which augments athletic goodwill. Recursively solving equation (2) results in, ${ }^{21}$

$$
G_{j t}^{a}=\sum_{\ell=0}^{t-1}\left(\lambda^{a}\right)^{\ell} b^{a} A_{j, t-\ell}+\left(\lambda^{a}\right)^{t} G_{j 0}^{a} .
$$

I introduce individual-level preference heterogeneity by the sixth and seventh terms in equation (1), of which elements of $\nu$ are assumed to be distributed from a standard normal distribution. Hence, the characteristic $x_{\text {sikt }}$ factors into the utility function through the mean component $\beta_{k}^{a} x_{s j k t}$ plus any deviations from the mean $\sigma_{k}^{a} x_{s j k t} \nu_{i s k}$ that differ by individuals. Similarly, $\gamma^{a} p_{s j t}^{T}$ represents the mean disutility one gets from tuition expenses, and $\sigma_{p}^{a} p_{s j t}^{T} \nu_{i s p}$ represents any deviations from this mean, thus allowing different price elasticities by individual. The utility one gets for not applying to college $j$ is given as, ${ }^{22}$

$$
u_{i s 0 t}^{a}=\xi_{s 0 t}^{a}+\sigma_{0}^{a} \nu_{i s 0}+\varepsilon_{i s 0 t}^{a} .
$$

One can think of $\xi_{s 0 t}^{a}$ as common shocks within markets that influence choice. For example, in 2005 Hurricane Katrina made it difficult for students in Louisiana to apply to college. I capture individual-level heterogeneity in the value of not applying to school $j$ by the second term in equation (4). Since the market shares in the logit model are a function of the differences in utility from the outside option (not to apply to $j$ ), naturally, in this formulation the random coefficient on the intercept term of the utility of option $j$ captures the heterogeneity of the outside option of not applying to $j$.

The utility function in equation (1) can be decomposed as

$$
\begin{aligned}
u_{i s j t}^{a} & =\delta\left(x_{s j t}, p_{s j t}^{T}, G_{j t}^{a}, \xi_{s j t}^{a} ; \theta_{1}^{a}\right)+\mu\left(x_{s j t}, p_{s j t}^{T}, \nu_{i s}^{a} ; \theta_{2}^{a}\right)+\varepsilon_{i s j t}^{a} \\
& =\delta_{s j t}^{a}+\mu_{i s j t}^{a}+\varepsilon_{i s j t}^{a},
\end{aligned}
$$

\footnotetext{
${ }^{21}$ With regards to the identification of the carryover rate $\lambda$ : In the data, if a school has more than two periods (current $+1^{\text {st }} \mathrm{lag}$ ) of football performance, one can uniquely identify the marginal effect of football success and the carryover rate separately. If there are more than two periods then these periods would act as over-identifying restrictions, hence, $\lambda$ can be more precisely identified.

${ }^{22}$ More precisely, the outside option here would be not applying to one of the 120 universities in Division 1 FBS.

Thus, deciding to apply to an Ivy League school would be captured by the outside option.
} 
where $\xi_{s j t}^{a}=\xi_{j}^{a}+\Delta \xi_{s j t}^{a}$ and $\delta\left(x_{s j t}, p_{s j t}^{T}, G_{j t}^{a}, \xi_{s j t}^{a} ; \theta_{1}^{a}\right)$ represents the mean utility, which is independent of individual characteristics $\nu_{i s}^{a}=\left(\nu_{i s p}^{a}, \nu_{i s 1}^{a}, \ldots, \nu_{i s K}^{a}\right)$, and $\mu\left(x_{s j t}, p_{s j i}^{T}, \nu_{i s}^{a} ; \theta_{2}^{a}\right)$ is the individual's deviations from the mean. Correspondingly, $\theta_{1}^{a}=\left(\gamma^{a}, \beta_{1}^{a}, \ldots, \beta_{K}^{a}, \lambda^{a}, b^{a}\right)$ is the vector of parameters that represents the marginal effect on utility for school-state characteristics independent from individual characteristics, and $\theta_{2}^{a}=\left(\sigma_{p}^{a}, \sigma_{1}^{a}, \ldots, \sigma_{K}^{a}\right)$ is the vector of parameters that is associated with these individual characteristics.

By the distributional assumption on the idiosyncratic shocks and the utility specification stated above, the probability of individual $i$ with ability $a$, who resides in state $s$, applying to institution $j$ is given as, ${ }^{23}$

$$
P_{i s j t}^{a}=\frac{\exp \left(\delta_{s j t}^{a}+\mu_{i s j t}^{a}\right)}{1+\exp \left(\delta_{s j t}^{a}+\mu_{i s j t}^{a}\right)} .
$$

By integrating over the heterogeneity component, one can obtain the overall proportion of students of ability $a$ in state $s$ that applied to $j$

$$
S_{s j t}^{a}=\int \frac{\exp \left(\delta\left(x_{s j t}, p_{s j t}^{T}, G_{j t}^{a}, \xi_{s j t}^{a} ; \theta_{1}^{a}\right)+\mu\left(x_{s j t}, p_{s j t}^{T}, \nu_{i} ; \theta_{2}^{a}\right)\right)}{1+\exp \left(\delta\left(x_{s j t}, p_{s j t}^{T}, G_{j t}^{a}, \xi_{s j t}^{a} ; \theta_{1}^{a}\right)+\mu\left(x_{s j t}, p_{s j t}^{T}, \nu_{i} ; \theta_{2}^{a}\right)\right)} h^{a}\left(\nu_{i}\right) d \nu_{i},
$$

where $h^{a}\left(\nu_{i}\right)$ is the joint distribution of all of the heterogeneity elements $\nu_{i}^{a}=\left(\nu_{i p}^{a}, \nu_{i 1}^{a}, \ldots, \nu_{i K}^{a}\right)$ for a student with ability $a$. Since the above equation involves solving a multidimensional integral that has no closed-form solution, one has to rely on simulations to obtain the overall application shares.

\section{Estimation}

\subsection{Obtaining application shares}

The IPEDS data contain the number of applications received for each institution in a given year. However, they do not contain the market (state) from which these applications originate. Therefore, the application shares (proportion of students in state $s$ that applies to

\footnotetext{
23 The application decision is assumed to be independent across schools. This assumption may sound somewhat limited. However, since the cost of applications is extremely small compared to the cost of attendance, this assumption is not overly restrictive.
} 
j) are obtained by synchronizing the College Board SAT and IPEDS data, specifically, the percentage of SAT scores sent to each institution from each state and the number of applications each school received. I hereafter refer to application shares as the proportion of high school students in state $s$ who send an application to a particular institution, formally defined as,

$$
S_{s j t}=\frac{\# \text { of high school students from state } s \text { that applies to institution } j}{\text { Total \# of high school students (seniors) in state } s} .
$$

Naturally, these shares will not sum to one since an individual may choose to apply to more than one school; so the term 'share' is somewhat awkward. The application share can be thought of as the proportion of students who consider school $j$ and, hence, apply to $j$ from the total number of high school students in state $s$.

The College Board SAT data contain the exact number of SAT score reports sent to any institution from a particular state. Although merely sending one's SAT score report to a school is not the same as applying (but would probably be a superset), once we know the ratio of the SAT score reports sent to an institution from a specific state and the number of total applications the institution received, we can infer the number of applications coming from a particular state for each institution. Specifically, suppose that there are $S$ markets and $J$ institutions. Let the ratio of SAT score reports sent from students in market $s$ to institution $j$ be $\mu_{j}^{s}$, formally defined as,

$$
\mu_{j}^{s}=\frac{\# \text { students in } s \text { who sent SAT scores to } j}{\# \text { total students in } s \text { who sent SAT scores }} .
$$

In addition, let the total market size (i.e., the total number of high school graduates) of state $s$ be $M^{s}$ and the total number of applications received by $j$ be $A_{j}$. Since $\mu_{j}^{s}$ reflects the popularity (in applications) of school $j$ among students in $s$, I can obtain the number of applications coming from state $s$ for institution $j$ by utilizing this ratio and weighing it by the total number of high school students in each state $s$, such that,

$$
A_{j}^{s}=\frac{\mu_{j}^{s} \cdot M^{s}}{\sum_{r=1}^{S} \mu_{j}^{r} \cdot M^{r}} \cdot A_{j},
$$


4.2 Order statistics to infer the quality of applicants

Federal law protects the data associated with individual information about the applicants to each institution of higher education in the United States. ${ }^{24}$ Thus, I can obtain only the data on the quality of students (SAT scores) for the enrolled student population for each academic institution in my sample. Relying on this information along with the admission and enrollment rates, I use order statistics to infer the quality of the applicants. I first assume that each institution stochastically admits the top proportion of applicants. Since each institution wants to attract students of higher ability, this assumption does not seem all that unreasonable. I further assume that the bottom proportion of the accepted students stochastically decides to enroll, since students with lower ability likely have fewer options to choose from.

Let us suppose that a certain institution admits $n-k+1$ out of $n$ applicants (where $1 \leq k \leq n$ ). Then, assuming that the school chooses the top $n-k+1$ out of $n$ students, we can construct an order statistics distribution from any number of underlying distributions. ${ }^{25}$ Let $X_{i}$ be a random variable that has a cumulative distribution function $F(x)$. If one were to randomly draw $n$ samples from this distribution and arrange them in a non-decreasing order, one would obtain the corresponding order statistics $X_{1: n}, X_{2: n}, \ldots, X_{n: n}$. These order statistics are naturally random variables whose distribution is a function of the underlying distribution. Specifically, the cumulative distribution function for the $k$-th highest order statistic is given as

$$
F_{k: n}(x)=\operatorname{Pr}\left(X_{k: n} \leq x\right)=\sum_{r=k}^{n} \frac{n !}{r !(n-r) !}\{F(x)\}^{r}\{1-F(x)\}^{n-r}
$$

and the cumulative distribution function for the combination of the $k \sim n$ highest bracket of order statistics is given as

$$
F_{(k: n): n}(x)=\frac{1}{n-k+1} \sum_{r=k}^{n} F_{r: n}(x) .
$$

\footnotetext{
${ }^{24}$ In order to obtain individual-level information for applicants (SAT scores), one would need to get permission from each academic institution and further from each student who applied to those institutions.

${ }^{25}$ Interested readers can refer to Sarhan and Greenberg (1962), Harter and Balakrishnan (1996, 1997), David (1981), Balakrishnan and Cohen (1991), and Arnold et al. (1992).
} 
Further, let us suppose that out of the $n-k+1$ admitted, the bottom $l$ students stochastically decide to enroll. Then, similarly, the cumulative distribution function for the $l$ th highest order statistic is given as

$$
H_{l: n-k+1}(x)=\sum_{r=l}^{n-k+1} \frac{(n-k+1) !}{r !(n-k+1-r) !}\left\{F_{(k: n): n}(x)\right\}^{r}\left\{1-F_{(k: n): n}(x)\right\}^{n-r}
$$

and, likewise, the cumulative distribution function for the $1 \sim l$ bracket of order statistics is given as

$$
H_{(1: l): n-k+1}(x)=\frac{1}{l} \sum_{r=1}^{l} H_{r: n-k+1}(x)
$$

Using these functions, I can recover the underlying distribution of the applicants' quality. Specifically, assuming that the SAT scores for applicants at institution $j$ are normally distributed with mean $\mu_{j}$ and variance $\sigma_{j}^{2}$, I can match the order statistics distribution that best fits the data to recover the underlying distribution of applicants. ${ }^{26}$

I observe the first and the third quartiles of the SAT scores for the enrolled freshmen class along with the admission and enrollment rates and, hence, use this information to construct a minimum-distance estimator to recover the parameters of the underlying distribution function. For example, suppose that institution $j$ admits 30 percent of its applicants and of the 30 percent that are admitted two thirds decide to enroll. This would mean that the top three out of ten applicants are admitted and out of the three that are admitted two decides to enroll. If the first and the third quartiles of the SAT scores are $Q_{j 25}$ and $Q_{j 75}$, respectively, then we can find the parameters of the underlying distribution function by minimizing the minimum distance estimator

$$
\theta_{j}=\arg \min \left\{\left(Q_{j 25}-H_{(1: l): n-k+1}^{-1}(0.25)\right)^{2}+\left(Q_{j 75}-H_{(1: l): n-k+1}^{-1}(0.75)\right)^{2}+\left(\bar{Q}_{j}-H_{(1: l): n-k+1}^{-1}(0.5)\right)^{2}\right\},
$$

${ }^{26}$ The minimum and the maximum SAT scores are 400 and 1600, respectively. Thus, in practice, the underlying distribution was assumed to come from a truncated normal distribution. 
where, in the current example, $k=8, l=2$, and $n=10$. Figure 5 shows the graphical illustration of this procedure. Hence, from the distributional information of the enrolled students, I can precisely obtain the mass of applicants via their SAT scores.

I observe the SAT distribution of students in each market and can infer (by equation (6)) the number of students who applied to each school from each state. Using this information and having obtained the distribution of the quality of applicants for each school, I am able to construct the application shares for any ability level in each market. In practice, I construct the applicant shares by five evenly-divided segments based on the overall SAT score distribution. In constructing the application shares by ability segment, I assume that the school's SAT distribution of applicants is identical across states. Although this assumption seems reasonable for private schools it may be somewhat problematic for public schools. However, since most of the applicants for public institutions predominantly come from their home state, this assumption would likely not bias the estimates in a severe way. To illustrate, Figure 6 shows the probability distribution of public schools and its composition of students (percentage of in-state students). ${ }^{27}$ As one can see the majority of the student body for most public schools in Division 1 FBS is composed of in-state students. More than $35 \%$ of public schools have $90 \%$ or more of its students from its home state while only $10 \%$ of them have less than $70 \%$ with none of them having less than $62 \% .^{28}$

\subsection{Estimation procedure}

I use the generalized method of moments (GMM; Hansen, 1982) to estimate the model parameters. The GMM is a generic method for estimating parameters in an econometric model without relying on any distributional assumptions on the statistical error structure. Furthermore, the GMM allows us to use instrumental variables to correct for the likely correlation between certain variables (e.g., price) and the unobserved errors. However, in the

\footnotetext{
27 Source: "Percentage of Out-of-State at Public Universities," CollegeXpress.com.

28 To further validate this assumption, Figure 7 shows the SAT score (math) distribution for an anonymous mid-size east coast public institution for its in-state and out-of-state enrolling students. Roughly about $10 \%$ of this institution's incoming freshmen class was from out-of-state. Although, the out-of-state distribution seem to be skewed slightly towards the right, there is only a small difference between in-state and out-of-state. Likewise, the difference of SAT scores between in-state and out-of-state students were minimal with average SAT scores (math+reading) for in-state and out-of-state students being 1123 and 1139, respectively.
} 
current structure, since the unobserved error component enters the share equation in (5) nonlinearly, it is not feasible to directly apply the instrumental variables technique. I therefore use the approach of Berry et al. (1995), which has been widely applied in the marketing literature (e.g., Sudhir, 2001; Gordon and Hartmann, 2012). ${ }^{29}$

For the initial values of goodwill $G_{j 0}^{a}$, one can structure a distributional assumption and integrate over it or, with a long enough time series in the panel and the belief that the carryover rate is relatively small, one can start off with some initial number. The time series of the IPEDS and College Board SAT data in my sample is for nine years (2001-2009) and that of the athletics data is for 15 years (1996-2010). Hence, I have a sufficient amount of past athletic performance data and, thus, use the information from the entire history of athletic performance to set the initial goodwill stock, specifically as

$$
G_{j 0}^{a}=\frac{1}{1-\lambda^{a}} \cdot \frac{1}{T} \sum_{\ell=1}^{T} b^{a} A_{j k}
$$

in the estimation procedure.

4.4 The choice of variables and instruments

For school characteristics, I use the average faculty salary and the faculty-student ratio, variables that are commonly used in the literature to control for the quality of education. I use the distance in miles from a student's home state to an institution for school-market characteristics to take into account any psychological and monetary costs of being away from home. Furthermore, I use the annual borrowing rate to account for the opportunity cost of postsecondary education.

I use the number of overall football wins in a season for current athletic performance. As mentioned in Section 2.2, the more wins in a season, the more likely the team receives greater media exposure; therefore, the number of total wins in a season is a good proxy for current athletic success. The college football season ends in early January, with the final game being the BCS National Championship game. For the teams that do not qualify for the post-season bowl games (teams with fewer than six regular season wins), the season ends around Thanksgiving Day, with the conclusion of their main rivalry games. For the teams

${ }^{29}$ I direct readers to Berry et al. (1995), Nevo $(2000,2001)$ for details of the estimation procedure. 
that qualify for a bowl game, the season ends with the conclusion of the bowl game sometime in late December or early January, depending on which bowl game the team was invited to participate. Application packets, though they vary by institution and individual, are usually submitted around this time for the next academic year. So for a measure of current athletic performance I use the previous academic year's overall football wins.

The unobserved (by the econometrician but fully observed by the student and the school) time-varying common component $\Delta \xi$, which represents difficult to quantify features, may be correlated with tuition. While it is merely a given fact that, with profit-maximizing firms, prices are correlated with $\Delta \xi$, this is somewhat less obvious with educational institutions. It is highly unlikely that tuition is a flexible decision variable that one can systematically change over a short period of time. Nevertheless, I use the previous two years' tuition as instruments for current tuition.

By using an extensive set of school fixed effects, I am able to capture omitted or unobserved characteristics of quality and, thus, partially address the endogeneity problem related to athletic success. However, $\Delta \xi$, which represents time-specific deviations, can be endogenous with athletic goodwill. To further address the endogeneity concern with regard to $\Delta \xi$ and athletic goodwill $G$, let us first discuss the possible factors that construct the unobserved $\Delta \xi$. First, one can think of $\Delta \xi$ as any media exposure that is not observed in the data. A successful movie filmed on campus or a special event such as a presidential debate would fall into this category. These events likely occur randomly, so the endogeneity problem is probably not a big concern.

The endogeneity issue is likely to be a problem if we think of $\Delta \xi$ as investments or the maturity of investments, such as the opening of a new residence hall or academic facility. Since the goodwill stock of athletics is a function of historical athletic success and athletic success is likely a function of past investments in athletics, there may be a chance that $\Delta \xi$ and $G$ are correlated. I have several reasons to believe this is probably not the case. First, in most of the schools in my sample, the budgets for athletics and academics are separate, as indicated in the report issued by the Knight Commission on Intercollegiate Athletics in 2009, 
which finds that presidents of major universities have limited control over the budgets of their respective athletic departments. ${ }^{30}$ Second, creating a strong athletics program predominantly takes a longer time than building facilities. Thus, even though the decision to invest in academic facilities and athletics may be correlated, due to the timing difference in the maturity of investments, the endogeneity concern is less severe. This further reduces the endogeneity problem. Hence, I believe that the endogeneity issue is not a big concern in my model specification.

\section{Results}

I begin by showing the results of the static model, where the carryover rate $\lambda$ is set to zero, and, thus, athletic goodwill is just a linear function of current athletic performance. Table 3 shows the results of the static model without individual heterogeneity in taste or ability for two model specifications. These would be the same as an ordinary least squares (OLS) and a two-stage least squares (2SLS) regression with the natural log of odds as the dependent variable - homogeneous aggregate logit.

The results show that athletic performance has a significantly positive effect. Average faculty salary, which acts as a proxy for the quality of the faculty, is positive and significant. The faculty-student ratio is positive but insignificant, possibly due to limited variations in the size of the faculty or the student body; thus, most of the effect will be absorbed by the school fixed effects. Both tuition and distance are negative and significant, implying that students receive disutility from both the monetary cost of tuition and the mental cost of being away from home. The interest rate is negative and significant, suggesting that students value the opportunity cost with regard to postsecondary education.

The results of the OLS and 2SLS do not differ much. The elasticity of tuition increases slightly with the use of instrumental variables, but not as much as found in other studies, where the magnitude of increase is as much as twofold (e.g., Berry et al., 1995; VillasBoas and Winer, 1999). This probably is due to the fact that tuition may be close to being

\footnotetext{
30 Source: "Quantitative and Qualitative Research with Football Bowl Subdivision University Presidents on the Costs and Financing of Intercollegiate Athletics," Knight Commission on Intercollegiate Athletics, 2009.
} 
exogenous and is not as much of a flexible control variable that schools can easily adjust over a short period of time, as prices are for profit maximizing firms.

To further investigate this and find out if there exists any correlation between the number of applicants and tuition, I perform the following regression analysis. I first regress the percentage increase in the share of applications on the percentage increase in tuition. Specifically,

$$
\Delta p_{s j t}^{T}=\alpha+\kappa \Delta S_{s j t}+\eta_{s j t}
$$

where $\Delta S_{s j t}=\left(S_{s j t}-S_{s j(t-1)}\right) / S_{s j(t-1)}$ and $\Delta p_{s j t}^{T}=\left(p_{s j t}^{T}-p_{s j(t-1)}^{T}\right) / p_{s j(t-1)}^{T}$. If it turns out that the coefficient $\kappa$ is positive and significant, then tuition is endogenous. Specifically, there is a simultaneity bias. Furthermore, I regress the lag of the percentage changes in applications on changes in tuition to see whether schools adjust tuition levels for positive changes in past applications. Table 4 shows the estimates from both specifications. The coefficient with regard to the percentage change in the share of applicants is insignificant in both models, so the similarities between the results of the OLS and 2SLS are probably due to the fact that tuition is close to being exogenous in the data.

Table 5 shows the results of the static model with heterogeneity in both taste and ability. To allow for heterogeneity in taste for athletic success, I include a random coefficient for current athletic performance. In other words, the goodwill function in equation (1) is simply $G_{j t}^{a}=b^{a} A_{j t}$ with $\sigma_{A}^{a} A_{j t} \nu_{i s A}$ added on to allow for heterogeneity in taste for athletic performance. More specifically, the model I estimate here is

$$
u_{i s j t}^{a}=\sum_{k} \beta_{k}^{a} x_{s j k t}-\gamma^{a} p_{s j t}^{T}+b^{a} A_{j t}+\xi_{j}^{a}+\Delta \xi_{s j t}^{a}+\sum_{k} \sigma_{k}^{a} x_{s j k t} \nu_{i s k}+\sigma_{p}^{a} p_{s j t}^{T} \nu_{i s p}+\sigma_{A}^{a} A_{j t} \nu_{i s A}+\varepsilon_{i s j t}^{a} .
$$

Furthermore, I partition the student population into five evenly-divided segments based on the overall SAT scores and construct applicant shares by each market and segment to estimate segment level parameters. The range of SAT scores for the different segments is shown in the top row of Table $5 \mathrm{a}$ and is presented graphically in Figure 8. Athletic performance is positive and significant for all segments. The average faculty salary is also positive and significant. However, the mean utility parameter for athletic performance is greatest for students with low SAT scores and lowest for those with high SAT scores. The magnitude is as much as three 
times as large for the lowest-ability segment compared to that of the highest-ability segment, implying that athletic success is relatively more important to students with low academic ability. We can clearly see that the relative importance of athletic performance decreases with students' SAT scores, implying that students with higher ability, while somewhat fond of the success of a school's athletic program, are less enthusiastic about it than lower-ability students. ${ }^{31}$

With regard to the quality of education, the relative importance of average faculty salary, which proxies for the quality of the faculty, increases with SAT scores, indicating that the demand for high-quality education increases with students' academic ability. The effect of the faculty-student ratio, though insignificant for all segments, dramatically increases with student ability, which again implies that higher-ability students care relatively more about academics than their lower-ability counterparts do.

The coefficients on tuition and distance are all negative and highly significant. The effect of the interest rate is negative and significant for all segments, with the highest-ability segment being the most sensitive. Although this result may come as a surprise, it makes intuitive sense in that students with higher ability probably have a greater opportunity cost with regard to postsecondary education. The heterogeneity parameters are, for the most part, insignificant, except for tuition and distance for a number of segments. Even for the significant parameters, the magnitude is negligibly small, showing close to no heterogeneity in taste. It is probably the case that the extensive set of school fixed effects is absorbing most of the heterogeneity. Overall, all students are positively affected by a school's success on the field, even the highest-quality students, surprisingly. However, the relative importance is stronger for students with lower ability.

Table 6 shows the results of the dynamic model. For the dynamic model, I allow for heterogeneity only in student ability since the heterogeneity parameters on taste in the static

\footnotetext{
31 An alternative approach to incorporate (continuous) observed heterogeneity would be to draw student quality from the observed SAT distribution and interact it with the athletic performance variable, the number of wins. The results of this model specification are reported in Table 5b. The interaction term with regard to SAT scores and football success is negative and significant, consistent with the results of the model that incorporates discretelevel observed heterogeneity. I thank an anonymous reviewer for suggesting this robustness check.
} 
model show that it is negligible. Athletic performance, once again, is highly significant for all segments, with the lowest segment showing a much stronger preference for it compared to the higher-ability segments. The carryover rate $\lambda$ is significant for only the lower-ability segments, implying that athletic goodwill from the previous years remains relevant only to students with low ability.

Counterfactual analysis

The natural counterfactual to perform is to determine how significant athletic success is in attracting potential candidates to apply to a specific institution. Table 7a shows the "what if" scenario: What happens if a mid-level school that used to have a mediocre football team suddenly performs well on the field, with everything else held constant? ${ }^{32}$ I define mediocre performance as winning only four games per season in the previous two years and performing well as winning ten games per season in the past two years. Overall, applications increase by 18.7 percent when the school has a higher level of athletic success. However, a vast majority of the applicants come from the lower-ability segments. If a school wanted to simply match the increase in the total number of applications without having athletic success, it would have to decrease tuition by 3.8 percent or attract better faculty, who would be paid five percent more in the academic labor market. Of course, due to differences in preferences for academic quality or athletic success by students of different ability, the composition of the increase in applicants will be different, depending on whether it results from lower tuition, improved academic quality, or athletic success. Tables $7 \mathrm{~b}$ and $7 \mathrm{c}$ show the percentage increase in applications by students of different ability when the quality of faculty improves and when tuition falls, respectively, to equal the increase in applications from success on the field. One can see that the increase in applications is spread more evenly among segments when tuition decreases and that improvement in the quality of faculty affects high-ability students more than low-ability students. These findings are in contrast with the effect that athletic success has on different ability segments. Moreover, each additional win for a school results in an

${ }^{32}$ I define mid-level school as a school with median fixed effects estimates. 
additional loss to another school. Hence, this counterfactual exercise potentially underestimates the effect of athletic success. ${ }^{33}$

Building upon this analysis, the next apparent counterfactual is to look at how athletic success affects the selectivity of schools. Schools care about selectivity, particularly, the admissions rate, since it is used as one of the key evaluation criteria in determining the quality rankings of an academic institution. Tables 8 show the computed admissions rates of schools in the 25th, 50th, and 75th percentiles in accordance with their average SAT scores, with low and high athletic success. Once again, low and high athletic success are defined as winning four and ten games per season in the previous two seasons, respectively.

In computing this counterfactual, I keep the observed (estimated via order statistics) school's admission rates, which are different for each segment, constant. The logic behind this counterfactual is that schools making admissions decisions are not basing their evaluations on SAT scores alone. There are other factors that go into the decision making process, such as high school grades and extracurricular activities, and the admissions rate I observe in the data for each segment corresponds with this admissions policy. ${ }^{34}$ For example, suppose school A's admissions rate in the lowest-ability segment is 15 percent. This means that, although the students in this segment have relatively low SAT scores, 15 percent of them have other dimensions of quality (mentioned above) that makes them worthwhile for the school to attract. This form of admissions policy takes into account the policies of schools, which sometimes require, by state law, to admit students that surpass a certain quality level (not necessarily SAT scores). ${ }^{35}$ Since I observe (estimated via order statistics) the distribution of applicants and admittees, I can compute the actual admissions rates for each segment for each school. I compute the total admissions rates for low and high athletic success, keeping the school's segment-level admissions rates constant.

\footnotetext{
${ }^{33}$ I thank an anonymous reviewer for this comment.

${ }_{34}$ This admissions policy is consistent with the assumption with regards to the use of order statistics distribution to back out student quality in Section 4.2 .

35 Texas House Bill 588, commonly referred to as the "Top 10\% Rule", is a Texas law passed in 1997. This bill guarantees Texas students who graduated in the top 10 percent of their high school class be given automatic admission to all state-funded universities.
} 
Tables 8 show that both private and public schools gain in selectivity through athletic success. For the median (in terms of average SAT scores) private school, selectivity rates improve by 2.1 percentage points, while for the median public school, selectivity rates improve by 2.6 percentage points.

\section{Conclusion}

Intercollegiate athletics has gained exponential growth in popularity over the past several decades and now plays a big part in many people's lives in the United States. Colleges and universities benefit from intercollegiate athletics in the form of monetary gain through ticket and merchandise sales, as well as lucrative television contracts, and in the form of advertising through school exposure in multimedia outlets.

The advertising effect of intercollegiate athletics was first speculated in the years following Boston College quarterback Doug Flutie's infamous game-winning Hail Mary touchdown pass against the University of Miami in 1984, when Boston College witnessed a substantial increase in its applications. The mass media thus coined the term "Flutie effect" to refer to an increase in the exposure and prominence of an academic institution due to the success of its athletics program. The Flutie effect, though conjectured to be quite large in magnitude, surprisingly has not been fully investigated in the academic literature. This study empirically investigates the Flutie effect to determine the relative importance of a school's athletic success compared to other factors influencing the choice of schools for students of different abilities.

To investigate the advertising effect of intercollegiate athletics, I apply a flexible random coefficients aggregate discrete choice model and treat athletic success and its cumulative performance as a stock of goodwill that decays over time but augments with current performance. I use market-level data to adequately control for different factors that affect a student's choice of postsecondary education at the market level, unlike previous research, which relies solely on aggregate data.

Furthermore, to overcome data limitations due to privacy regulations, I innovate and contribute to the broader line of research in discrete choice models by applying the use of an 
order statistics distribution to infer the quality of applicants from the observed distribution of the enrolling freshman class, allowing me to identify different preferences for students of different ability.

Overall, I find that athletic success has a significant impact on the quality and quantity of applicants to institutions of higher education in the United States. However, athletic success has relative more importance to the students with lower ability. On the other hand, I find that students of higher ability have a stronger preference for the quality of education compared to their lower-ability counterparts. Furthermore, the carryover rate of athletic goodwill is evident only for students with low SAT scores, suggesting that students with low ability value the historical success of intercollegiate athletics over longer periods of time. Nevertheless, surprisingly, students with high SAT scores are also significantly affected by athletic success.

In addition, I find that when a school goes from being mediocre to being great on the football field, applications increase by 18.7 percent. To attain similar effects, a school has to either decrease its tuition by 3.8 percent or increase the quality of its education by recruiting higher-quality faculty who are paid five percent more in the academic labor market. I also find schools become more selective with athletic success. For a mid-level school, in terms of average SAT scores, the admissions rate improves by 5.1 percent with high-level athletic success.

Why would athletic success have any impact on an academic institution's applications for admission? There may be several reasons. First, this effect may be due to simply an increase in awareness. There are many academic institutions in the United States and chances are that many of them are fairly unknown. So having a successful athletics program can increase the visibility of these institutions to students who have not yet decided on which school to apply to. Even for schools that are fairly well known, the buzz created from performance on the field can lead to stories on the evening news and in the sports pages of newspapers, which may further increase awareness of these schools.

One can go a little bit deeper. Sports are a big part of American culture. It is extremely common for people in the United States to make the sporting events of their alumni 
institutions the focal point of their social interactions. Students may find it appealing to take part in such social bonding over sports to make them feel as though they are a part of something special, something bigger than themselves. This can lead to a virtuous cycle of improvements in alumni engagement about the school, translating into donations and help with job placements for current students, which in turn leads to greater school success. Although, not addressed in the current analysis, the question of 'why' students value intercollegiate athletics can be an exciting venue for future research. 


\section{References}

Arnold, B.C., N. Balakrishnan, H.N. Nagaraja (1992), A First Course in Order Statistics, John Wiley \& Sons, New York.

Assmus, G., J.U. Farley, D.R. Lehmann (1984), "How Advertising Affects Sales: Meta-Analysis of Econometric Results," Journal of Marketing Research, 21(1), pp. 65-74.

Balakrishnan, N., A.C. Cohen (1991), Order Statistics and Inference: Estimation Methods, Academic Press, San Diego.

Berry, S. (1994), "Estimating Discrete Choice Models of Product Differentiation," Rand Journal of Economics, 25(2), pp. 242-262.

Berry, S., J. Levinsohn, A. Pakes (1995), "Automobile Prices in Market Equilibrium," Econometrica, 63(4), pp. 841-890.

Bruce, N. (2008), "Pooling and Dynamic Forgetting Effects in Multi-Theme Advertising: Tracking the Advertising Sales Relationship with Particle Filters," Marketing Science, 27(4), pp. 659-673.

Clarke, D.G. (1976), "Econometric Measurement of the Duration of Advertising Effect on Sales," Journal of Marketing Research, 13(4), pp. 345-357.

David, H. A. (1981), Order Statistics, 2nd ed., John Wiley \& Sons, New York.

Dekimpe, M.G., D.M. Hanssens (1995), "The Persistence of Marketing Effects on Sales," Marketing Science, 14(1), pp. 1-21.

De Kluyver, C.A., R.J. Brodie (1987), "Advertising-versus-Marketing Mix Carryover Effects: An Empirical Investigation," Journal of Business Research, 15, pp. 269-287.

Givon, M., D. Horsky (1990), "Untangling the Effects of Purchase Reinforcement and Advertising Carryover," Marketing Science, 9(2), pp. 171-187.

Gordon, B.R., W. Hartmann (2012), "Advertising Effects in Presidential Elections," Working paper, Columbia University.

Hansen, P. (1982), "Large Sample Properties of Generalized Method of Moments Estimators," Econometrica, 50(4), pp. 1029-1054.

Harter, H.L., N. Balakrishnan (1996), CRC Handbook of Tables for the Use of Order Statistics in Estimation, CRC Press, Boca Raton, FL.

Hatter, H.L., N. Balakrishnan (1997), Tables for the Use of Range and Studentized Range in Tests of Hypotheses, CRC Press, Boca Raton, FL. 
Lodish, L.M., M.M. Abraham, J. Livelsberger, B. Lubetkin, B. Richardson, M.E. Stevens (1995), "A Summary of Fifty-Five In-Market Experimental Estimates of the Long-Term Effect of TV Advertising," Marketing Science, 14(3), pp. 133-140.

McCormick, R.E., M. Tinsley (1987), "Athletics versus Academics? Evidence from SAT Scores," Journal of Political Economy, 95(5), pp. 1103-1116.

Murphy, R.G., G. Trandel (1994), "The Relation between a University's Football Record and the Size of Its Applicant Pool," Economics of Education Review, 13(3), pp. 265-270.

Nevo, A. (2000), "A Practitioner's Guide to Estimation of Random Coefficients Logit Models of Demand," Journal of Economics 83 Management Strategy, 9(4), 513-548.

Nevo, A. (2001), "Measuring Market Power in the Ready-to-Eat Cereal Industry," Econometrica, 69(2), 307-342

Pope, D.G., J. Pope (2009), "The Impact of College Sports Success on the Quantity and Quality of Student Applications," Southern Economic Journal, 75(3), pp. 750-780.

Rutz, O.J., R. Bucklin (2011), "From Generic to Branded: A Model of Spillover Dynamics in Paid Search Advertising," Journal of Marketing Research, 48(1), pp. 87-102.

Sarhan, A.E., B. Greenberg (1962), Contributions to Order Statistics, John Wiley \& Sons, New York.

Sudhir, K. (2001), "Competitive Pricing Behavior in the Auto Market: A Structural Analysis," Marketing Science, 20(1), pp. 42-60.

Tucker, I.B., L. Amato (1993), "Does Big-Time Success in Football or Basketball Affect SAT Scores?" Economics of Education Review, 12(2), pp. 177-181.

Villas-Boas, J.M., R.S. Winer (1999), "Endogeneity in Brand Choice Models," Management Science, 45(10), pp. 1324-1338. 
Table 1: Descriptive statistics

\begin{tabular}{|c|c|c|c|c|c|c|}
\hline & \multicolumn{2}{|c|}{ Total } & \multicolumn{2}{|c|}{$\mathrm{AQ}$} & \multicolumn{2}{|c|}{ Non-AQ } \\
\hline & Public & Private & Public & Private & Public & Private \\
\hline \multirow{2}{*}{ No. of applications } & 13,797 & 15,184 & 17,139 & 18,971 & 9,841 & 9,907 \\
\hline & $(8,434)$ & $(8,298)$ & $(8,478)$ & $(7,436)$ & $(6,433)$ & $(6,319)$ \\
\hline \multirow{2}{*}{$\begin{array}{c}\text { Size of undergraduate } \\
\text { population }\end{array}$} & 20,636 & 9,517 & 23,833 & 9,632 & 16,851 & 9,356 \\
\hline & $(8,111)$ & $(6,381)$ & $(7,578)$ & $(3,478)$ & $(7,017)$ & $(8,976)$ \\
\hline \multirow{2}{*}{ Admission rate } & 0.69 & 0.43 & 0.67 & 0.37 & 0.72 & 0.51 \\
\hline & $(0.18)$ & $(0.19)$ & $(0.17)$ & $(0.17)$ & $(0.20)$ & $(0.19)$ \\
\hline \multirow{2}{*}{ Enrollment rate } & 0.48 & 0.39 & 0.46 & 0.37 & 0.50 & 0.41 \\
\hline & $(0.14)$ & $(0.15)$ & $(0.12)$ & $(0.12)$ & $(0.16)$ & $(0.19)$ \\
\hline \multirow{2}{*}{ No. of faculty } & 1,074 & 829 & 1370 & 935 & 723 & 681 \\
\hline & $(556)$ & $(364)$ & $(552)$ & $(361)$ & $(293)$ & $(312)$ \\
\hline \multirow{2}{*}{ Faculty salary } & 70,265 & 86,477 & 75,629 & 89,303 & 63,914 & 82,539 \\
\hline & $(18,407)$ & $(18,051)$ & $(17,385)$ & $(20,735)$ & $(17,542)$ & $(12,414)$ \\
\hline \multirow{2}{*}{ Faculty-student ratio } & 0.05 & 0.10 & 0.06 & 0.11 & 0.05 & 0.10 \\
\hline & $(0.02)$ & $(0.05)$ & $(0.02)$ & $(0.05)$ & $(0.02)$ & $(0.04)$ \\
\hline \multirow{2}{*}{ SAT scores } & 1,117 & 1,306 & 1,167 & 1,326 & 1,057 & 1,278 \\
\hline & $(95)$ & $(95)$ & $(77)$ & $(89)$ & $(80)$ & (96) \\
\hline
\end{tabular}

* Years 2001 - 2009, for 120 schools participating in Division 1 FBS. Standard deviation is reported in parenthesis.

Table 2: Overall football wins per season, selective schools

\begin{tabular}{l|rrrrrrrrr}
\hline & 2000 & 2001 & 2002 & 2003 & 2004 & 2005 & 2006 & 2007 & 2008 \\
\hline Notre Dame & 9 & 5 & 10 & 5 & 6 & 9 & 10 & 3 & 7 \\
Penn St. & 5 & 5 & 9 & 3 & 4 & 11 & 9 & 9 & 11 \\
Texas & 9 & 11 & 11 & 10 & 11 & 13 & 10 & 10 & 12 \\
Oregon & 10 & 11 & 7 & 8 & 5 & 10 & 7 & 9 & 10 \\
West Virginia & 7 & 3 & 9 & 8 & 8 & 11 & 11 & 11 & 9 \\
\hline
\end{tabular}


Table 3: Homogeneous aggregate logit

\begin{tabular}{c|r|r}
\hline & \multicolumn{1}{|c|}{ OLS } & \multicolumn{1}{c}{ 2SLS } \\
\hline Interest rate & $\begin{array}{r}-0.234^{* * *} \\
(0.021)\end{array}$ & $\begin{array}{r}-0.237^{* * *} \\
(0.021)\end{array}$ \\
\hline Average faculty salary & $\begin{array}{r}0.042^{* * *} \\
(0.002)\end{array}$ & $\begin{array}{r}0.042^{* * *} \\
(0.002)\end{array}$ \\
\hline Faculty-student ratio & $\begin{array}{r}0.636 \\
(1.040)\end{array}$ & $(1.052)$ \\
\hline No. of wins & $0.019^{* * *}$ & $0.019^{* * *}$ \\
$(0.004)$ & $(0.004)$ \\
\hline Distance & $-0.034^{* * *}$ & $-0.034^{* * *}$ \\
$(0.002)$ & $(0.002)$ \\
\hline Tuition & $-0.155^{* * *}$ & $-0.157^{* * *}$ \\
& $(0.002)$ & $(0.002)$ \\
\hline \multicolumn{2}{|c}{} &
\end{tabular}

Table 4: Testing for endogeneity

\begin{tabular}{c|r|r}
\hline Dependent variable & $\begin{array}{r}\text { Percentage change } \\
\text { in tuition }\end{array}$ & $\begin{array}{c}\text { Percentage change } \\
\text { in tuition }\end{array}$ \\
\hline Model type & Model 1 & \multicolumn{1}{c}{ Model 2 } \\
\hline Constant & $0.050^{* * *}$ & $0.046^{* * *}$ \\
$(0.001)$ & $(0.002)$ \\
\hline Percentage change & -0.007 \\
in applications & $(0.006)$ & 0.002 \\
\hline Percentage change & & $(0.009)$ \\
in applications (lag) & $* * * \mathrm{p}<0.01$. &
\end{tabular}


Table 5a: Parameter estimates, static model

\begin{tabular}{|c|c|c|c|c|c|c|}
\hline & & seg1 & seg2 & seg3 & $\operatorname{seg} 4$ & seg 5 \\
\hline & SAT score range & $\begin{array}{l}0- \\
837\end{array}$ & $\begin{array}{c}837- \\
973\end{array}$ & $\begin{array}{l}973- \\
1090\end{array}$ & $\begin{array}{l}1090- \\
1225\end{array}$ & $\begin{array}{c}1225- \\
1600\end{array}$ \\
\hline \multirow{7}{*}{$\theta_{1}$} & Constant & $\begin{array}{r}-3.179^{* * *} \\
(0.340) \\
\end{array}$ & $\begin{array}{r}-2.810^{* * *} \\
(0.244) \\
\end{array}$ & $\begin{array}{r}-2.667^{* * *} \\
(0.225) \\
\end{array}$ & $\begin{array}{r}-2.537^{* * *} \\
(0.224) \\
\end{array}$ & $\begin{array}{r}-2.270^{* * *} \\
(0.271) \\
\end{array}$ \\
\hline & Interest rate & $\begin{array}{r}-0.139 * * * \\
(0.035) \\
\end{array}$ & $\begin{array}{r}-0.192^{* * *} \\
(0.024) \\
\end{array}$ & $\begin{array}{r}-0.221^{* * *} \\
(0.022) \\
\end{array}$ & $\begin{array}{r}-0.252^{* * *} \\
(0.022) \\
\end{array}$ & $\begin{array}{r}-0.316^{* * *} \\
(0.026) \\
\end{array}$ \\
\hline & $\begin{array}{c}\text { Average faculty } \\
\text { salary }\end{array}$ & $\begin{array}{r}0.046^{* * *} \\
(0.003) \\
\end{array}$ & $\begin{array}{r}0.038^{* * *} \\
(0.002) \\
\end{array}$ & $\begin{array}{r}0.037^{* * *} \\
(0.002) \\
\end{array}$ & $\begin{array}{r}0.039^{* * *} \\
(0.002) \\
\end{array}$ & $\begin{array}{r}0.048^{* * *} \\
(0.002) \\
\end{array}$ \\
\hline & $\begin{array}{c}\text { Faculty-student } \\
\text { ratio }\end{array}$ & $\begin{array}{r}-1.650 \\
(1.918) \\
\end{array}$ & $\begin{array}{r}-0.469 \\
(1.411) \\
\end{array}$ & $\begin{array}{r}0.015 \\
(1.265) \\
\end{array}$ & $\begin{array}{r}0.474 \\
(1.217) \\
\end{array}$ & $\begin{array}{r}1.307 \\
(1.369) \\
\end{array}$ \\
\hline & \# Wins & $\begin{array}{r}0.035^{* * *} \\
(0.007)\end{array}$ & $\begin{array}{r}0.022^{* * *} \\
(0.005) \\
\end{array}$ & $\begin{array}{r}0.016^{* * *} \\
(0.005) \\
\end{array}$ & $\begin{array}{r}0.013^{* * *} \\
(0.005) \\
\end{array}$ & $\begin{array}{r}0.013^{* * *} \\
(0.005) \\
\end{array}$ \\
\hline & Distance & $\begin{array}{r}-0.030 * * * \\
(0.003) \\
\end{array}$ & $\begin{array}{r}-0.032^{* * *} \\
(0.003) \\
\end{array}$ & $\begin{array}{r}-0.036^{* * *} \\
(0.003) \\
\end{array}$ & $\begin{array}{r}-0.037^{* * *} \\
(0.004) \\
\end{array}$ & $\begin{array}{r}-0.045^{* * *} \\
(0.005) \\
\end{array}$ \\
\hline & Tuition & $\begin{array}{r}-0.154^{* * *} \\
(0.004) \\
\end{array}$ & $\begin{array}{r}-0.153^{* * *} \\
(0.003) \\
\end{array}$ & $\begin{array}{r}-0.156^{* * *} \\
(0.003) \\
\end{array}$ & $\begin{array}{r}-0.161^{* * *} \\
(0.003) \\
\end{array}$ & $\begin{array}{r}-0.179 * * * \\
(0.003) \\
\end{array}$ \\
\hline \multirow{7}{*}{$\theta_{2}$} & Constant & $\begin{array}{r}0.011 \\
(4.481) \\
\end{array}$ & $\begin{array}{r}0.012 \\
(2.644) \\
\end{array}$ & $\begin{array}{r}0.011 \\
(2.454) \\
\end{array}$ & $\begin{array}{r}0.012 \\
(2.396) \\
\end{array}$ & $\begin{array}{r}0.013 \\
(3.276) \\
\end{array}$ \\
\hline & Interest rate & $\begin{array}{r}0.008 \\
(0.427) \\
\end{array}$ & $\begin{array}{r}0.010 \\
(0.244) \\
\end{array}$ & $\begin{array}{r}0.010 \\
(0.222) \\
\end{array}$ & $\begin{array}{r}0.010 \\
(0.218) \\
\end{array}$ & $\begin{array}{r}0.009 \\
(0.303) \\
\end{array}$ \\
\hline & $\begin{array}{c}\text { Average faculty } \\
\text { salary }\end{array}$ & $\begin{array}{r}0.000 \\
(0.016) \\
\end{array}$ & $\begin{array}{r}0.000 \\
(0.010) \\
\end{array}$ & $\begin{array}{r}0.000 \\
(0.010) \\
\end{array}$ & $\begin{array}{r}0.000 \\
(0.009) \\
\end{array}$ & $\begin{array}{r}0.000 \\
(0.016) \\
\end{array}$ \\
\hline & $\begin{array}{c}\text { Faculty-student } \\
\text { ratio }\end{array}$ & $\begin{array}{r}0.012 \\
(6.605) \\
\end{array}$ & $\begin{array}{r}0.014 \\
(4.545) \\
\end{array}$ & $\begin{array}{r}0.011 \\
(3.981) \\
\end{array}$ & $\begin{array}{r}0.014 \\
(3.874) \\
\end{array}$ & $\begin{array}{r}0.010 \\
(4.890) \\
\end{array}$ \\
\hline & \# Wins & $\begin{array}{r}0.011 \\
(0.022) \\
\end{array}$ & $\begin{array}{r}0.012 \\
(0.015) \\
\end{array}$ & $\begin{array}{r}0.013 \\
(0.013) \\
\end{array}$ & $\begin{array}{r}0.012 \\
(0.013) \\
\end{array}$ & $\begin{array}{r}0.011 \\
(0.018) \\
\end{array}$ \\
\hline & Distance & $\begin{array}{r}0.015^{* * *} \\
(0.006)\end{array}$ & $\begin{array}{r}0.011 \\
(0.006) \\
\end{array}$ & $\begin{array}{r}0.013^{* *} \\
(0.007) \\
\end{array}$ & $\begin{array}{r}0.011 \\
(0.008) \\
\end{array}$ & $\begin{array}{r}0.010 \\
(0.013) \\
\end{array}$ \\
\hline & Tuition & $\begin{array}{r}0.011 \\
(0.008) \\
\end{array}$ & $\begin{array}{r}0.011^{* *} \\
(0.006) \\
\end{array}$ & $\begin{array}{r}0.012^{* *} \\
(0.005) \\
\end{array}$ & $\begin{array}{l}0.011^{* *} \\
(0.005)\end{array}$ & $\begin{array}{r}0.015^{* * *} \\
(0.006) \\
\end{array}$ \\
\hline
\end{tabular}


Table 5b: Parameter estimates, alternative static model

\begin{tabular}{|c|c|c|c|}
\hline \multicolumn{2}{|l|}{$\theta_{1}$} & \multicolumn{2}{|l|}{$\theta_{2}$} \\
\hline Constant & $\begin{array}{r}-2.659^{* * *} \\
(0.222) \\
\end{array}$ & Constant & $\begin{array}{r}0.013 \\
(2.456) \\
\end{array}$ \\
\hline Interest rate & $\begin{array}{r}-0.235^{* * *} \\
(0.022) \\
\end{array}$ & Interest rate & $\begin{array}{r}0.010 \\
(0.221) \\
\end{array}$ \\
\hline Average faculty salary & $\begin{array}{r}0.041^{* * *} \\
(0.002)\end{array}$ & Average faculty salary & $\begin{array}{r}0.000 \\
(0.008) \\
\end{array}$ \\
\hline Faculty-student ratio & $\begin{array}{r}0.503 \\
(1.251)\end{array}$ & Faculty-student ratio & $\begin{array}{r}0.009 \\
(2.512)\end{array}$ \\
\hline No. of wins & $\begin{array}{r}0.030^{* * *} \\
(0.004)\end{array}$ & $(\mathrm{SAT}) \times($ No. of Wins $)$ & $\begin{array}{c}-0.011^{* * *} \\
(0.003)\end{array}$ \\
\hline Distance & $\begin{array}{r}-0.038^{* * *} \\
(0.003) \\
\end{array}$ & Distance & $\begin{array}{r}0.014 \\
(0.008) \\
\end{array}$ \\
\hline Tuition & $\begin{array}{r}-0.159^{* * *} \\
(0.003)\end{array}$ & Tuition & $\begin{array}{r}0.014^{* * *} \\
(0.005)\end{array}$ \\
\hline
\end{tabular}

*** $\mathrm{p}<0.01$; SAT scores are scaled by 0.01 , i.e., SAT score of 1,600 would be 1.6.

Table 6: Parameter estimates, dynamic model

\begin{tabular}{|c|c|c|c|c|c|}
\hline & seg1 & seg2 & seg3 & $\operatorname{seg} 4$ & seg 5 \\
\hline SAT score range & $\begin{array}{c}0- \\
837\end{array}$ & $\begin{array}{c}837- \\
973\end{array}$ & $\begin{array}{l}973- \\
1090\end{array}$ & $\begin{array}{c}1090- \\
1225\end{array}$ & $\begin{array}{c}1225- \\
1600\end{array}$ \\
\hline Interest rate & $\begin{array}{r}-0.148^{* * *} \\
(0.036) \\
\end{array}$ & $\begin{array}{r}-0.199 * * * \\
(0.036) \\
\end{array}$ & $\begin{array}{r}-0.227^{* * *} \\
(0.036) \\
\end{array}$ & $\begin{array}{r}-0.256^{* * *} \\
(0.036) \\
\end{array}$ & $\begin{array}{r}-0.319^{* * *} \\
(0.036) \\
\end{array}$ \\
\hline Average faculty salary & $\begin{array}{r}0.046^{* * *} \\
(0.003) \\
\end{array}$ & $\begin{array}{r}0.037^{* * *} \\
(0.003) \\
\end{array}$ & $\begin{array}{r}0.037^{* * *} \\
(0.003) \\
\end{array}$ & $\begin{array}{r}0.039^{* * *} \\
(0.003) \\
\end{array}$ & $\begin{array}{r}0.048^{* * *} \\
(0.003) \\
\end{array}$ \\
\hline Faculty-student ratio & $\begin{array}{r}-1.465 \\
(1.817) \\
\end{array}$ & $\begin{array}{r}-0.313 \\
(1.802) \\
\end{array}$ & $\begin{array}{r}0.164 \\
(1.805) \\
\end{array}$ & $\begin{array}{r}0.612 \\
(1.808) \\
\end{array}$ & $\begin{array}{r}1.542 \\
(1.818) \\
\end{array}$ \\
\hline Distance & $\begin{array}{r}-0.024^{* * *} \\
(0.004) \\
\end{array}$ & $\begin{array}{r}-0.028^{* * *} \\
(0.004) \\
\end{array}$ & $\begin{array}{r}-0.031^{* * *} \\
(0.004) \\
\end{array}$ & $\begin{array}{r}-0.034^{* * *} \\
(0.004) \\
\end{array}$ & $\begin{array}{r}-0.041^{* * *} \\
(0.004)\end{array}$ \\
\hline Tuition & $\begin{array}{r}-0.154^{* * *} \\
(0.004) \\
\end{array}$ & $\begin{array}{r}-0.151^{* * *} \\
(0.004) \\
\end{array}$ & $\begin{array}{r}-0.155^{* * *} \\
(0.004) \\
\end{array}$ & $\begin{array}{r}-0.160 * * * \\
(0.004) \\
\end{array}$ & $\begin{array}{r}-0.176^{* * *} \\
(0.004)\end{array}$ \\
\hline \# Wins & $\begin{array}{r}0.034^{* * *} \\
(0.007)\end{array}$ & $\begin{array}{r}0.023^{* * *} \\
(0.007) \\
\end{array}$ & $\begin{array}{r}0.018^{* * *} \\
(0.007)\end{array}$ & $\begin{array}{c}0.014^{* *} \\
(0.007)\end{array}$ & $\begin{array}{r}0.014^{* *} \\
(0.007)\end{array}$ \\
\hline Carry-over rate & $\begin{array}{r}0.466^{* * * *} \\
(0.117) \\
\end{array}$ & $\begin{array}{r}0.524^{* * *} \\
(0.214)\end{array}$ & $\begin{array}{r}0.534^{* *} \\
(0.226) \\
\end{array}$ & $\begin{array}{r}0.535 \\
(0.314) \\
\end{array}$ & $\begin{array}{r}0.487 \\
(0.399) \\
\end{array}$ \\
\hline
\end{tabular}

*** $\mathrm{p}<0.01,{ }^{* *} \mathrm{p}<0.05$. 
Table 7: Percentage increase in applications by segment

a. Four wins per season vs. ten wins per season

\begin{tabular}{c|rrrrr}
\hline & seg1 & seg2 & seg3 & seg4 & seg5 \\
\hline $\begin{array}{c}\text { \% Increase } \\
\text { in applications }\end{array}$ & 34.38 & 22.96 & 17.42 & 8.93 & 8.67 \\
\hline
\end{tabular}

b. Five percent increase in mean faculty salary

\begin{tabular}{c|rrrrr}
\hline & seg1 & seg2 & seg3 & seg4 & seg5 \\
\hline $\begin{array}{c}\text { \% Increase } \\
\text { in applications }\end{array}$ & 20.37 & 16.30 & 16.29 & 17.02 & 21.24 \\
\hline
\end{tabular}

c. 3.8 percent decrease in tuition

\begin{tabular}{c|rrrrr}
\hline & seg1 & seg2 & seg3 & seg4 & seg5 \\
\hline $\begin{array}{c}\text { \% Increase } \\
\text { in applications }\end{array}$ & 17.95 & 17.74 & 18.19 & 18.81 & 20.73 \\
\hline
\end{tabular}

Table 8: Selectivity (admissions rate), four vs. ten wins per season

\begin{tabular}{c|rrr|rrr}
\hline \multirow{2}{*}{ School } & \multicolumn{3}{|c|}{ Low-success } & \multicolumn{3}{c}{ High-success } \\
\cline { 2 - 7 } & Total & Private & Public & Total & Private & Public \\
\hline $25^{\text {th }}$ percentile & $82.0 \%$ & $68.1 \%$ & $85.3 \%$ & $80.2 \%$ & $66.1 \%$ & $83.5 \%$ \\
$50^{\text {th }}$ percentile & $55.5 \%$ & $39.7 \%$ & $77.5 \%$ & $52.7 \%$ & $37.7 \%$ & $74.9 \%$ \\
$75^{\text {th }}$ percentile & $59.2 \%$ & $20.6 \%$ & $65.6 \%$ & $56.3 \%$ & $18.8 \%$ & $63.0 \%$ \\
\hline
\end{tabular}


Figure 1: NCAA Division I subdivisions and conferences

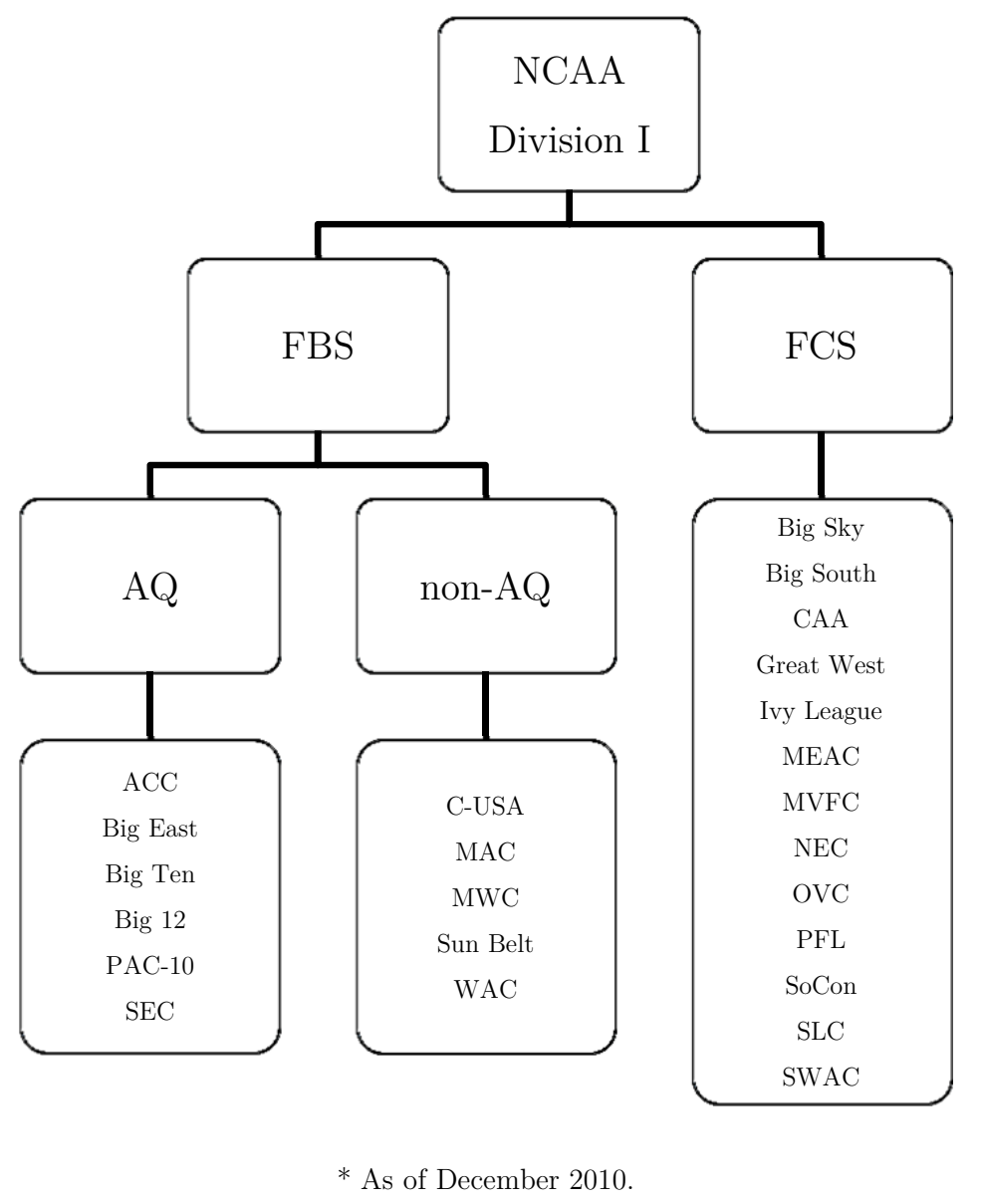


Figure 2: Trends for high school graduates and applications

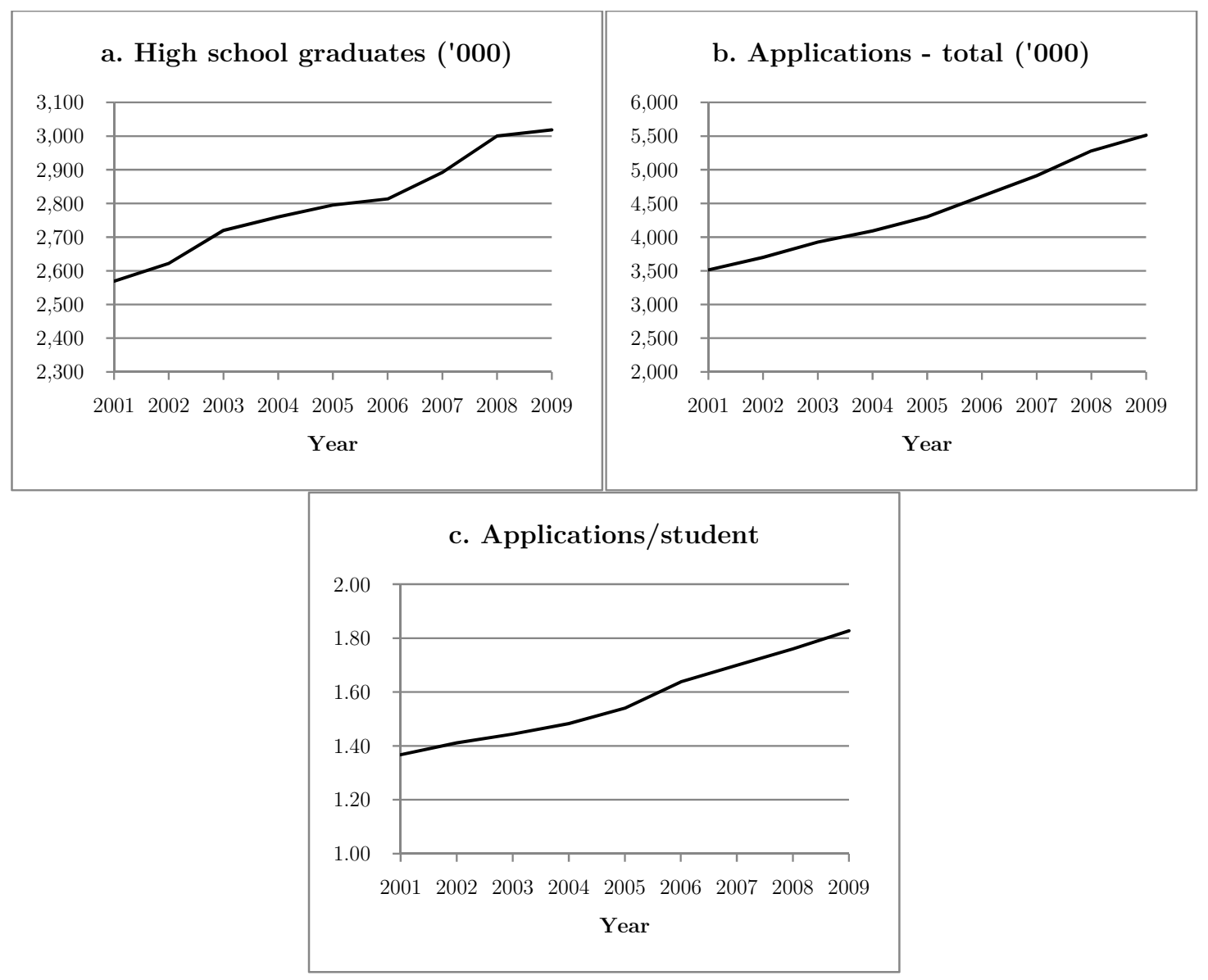


Figure 3: Applications, select schools
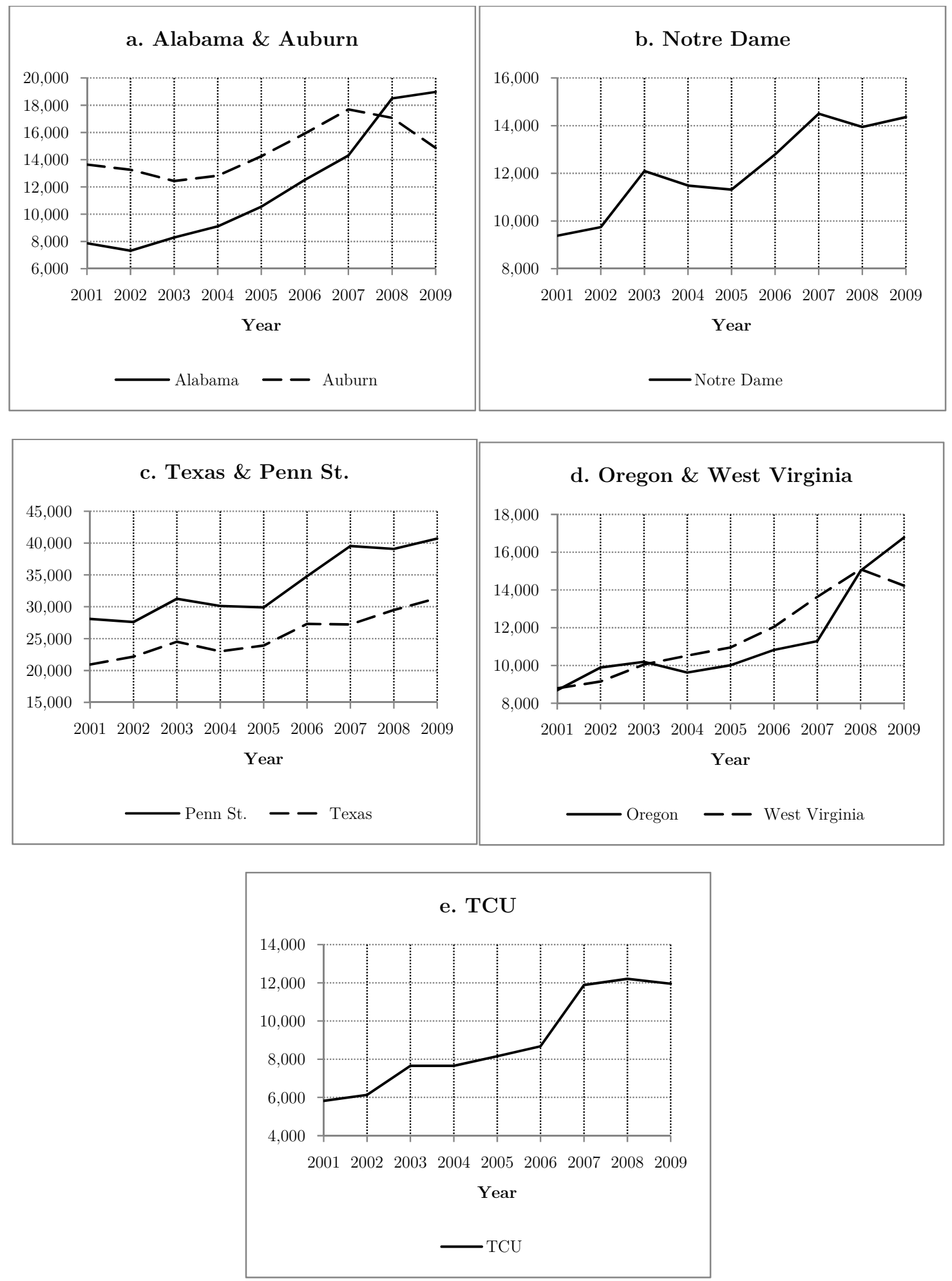
Figure 4: Applications and changes in the number of wins

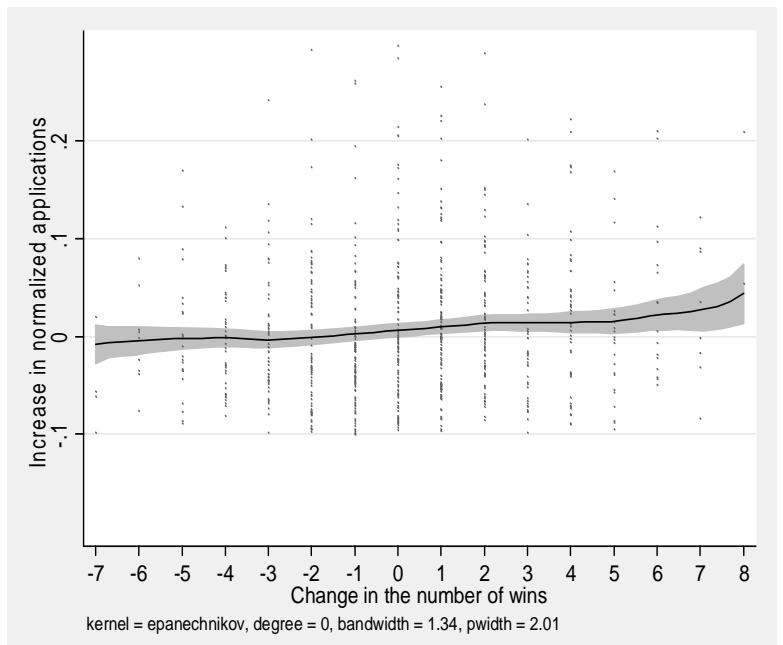

Figure 5: Distribution of SAT scores (mass)

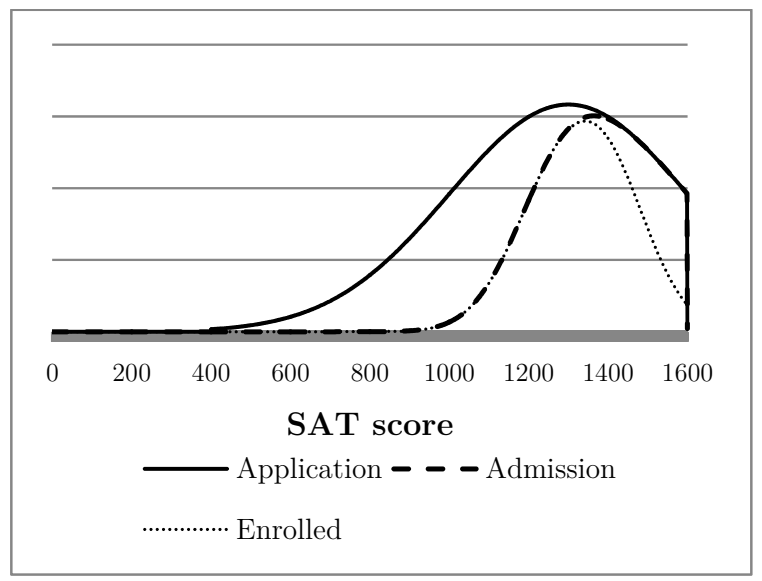

Figure 6: Distribution of the Percentage of In-State Students for Division 1 FBS Public Schools

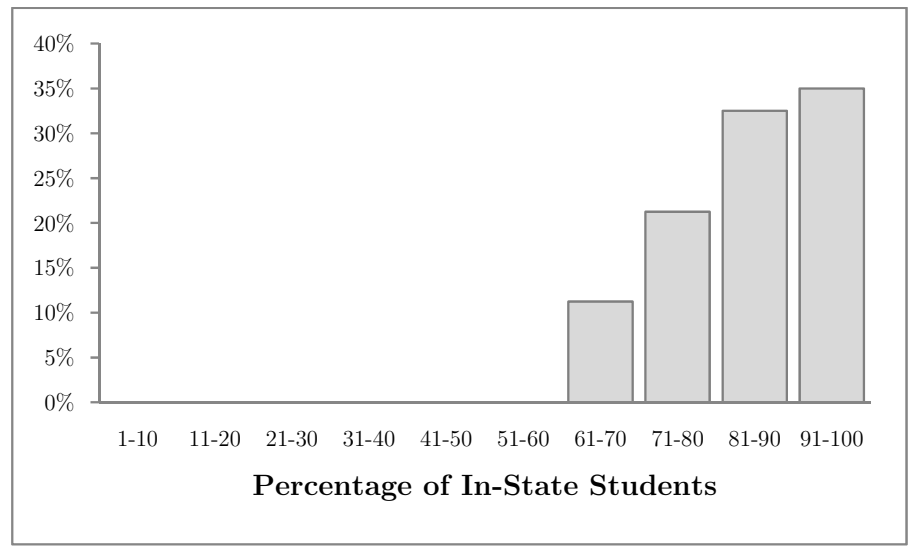


Figure 7: SAT Score (Math) Distribution of an Anonymous Mid-size Public Institution for In-state and Out-of-state Enrolling Students

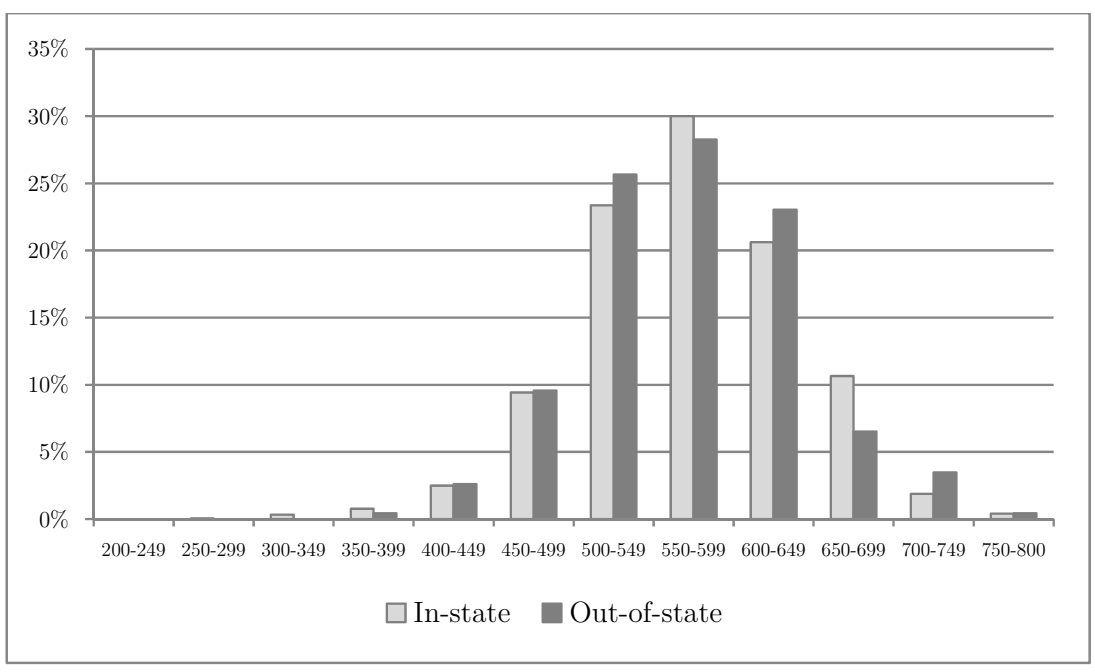

Figure 8: Segmentation based on SAT scores

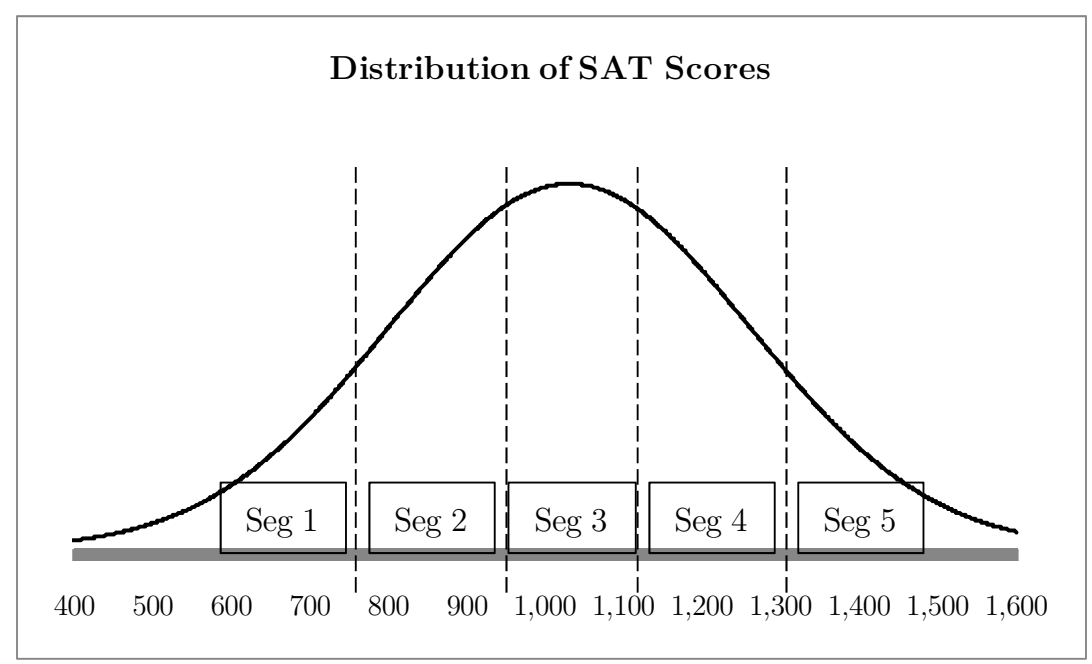

